\title{
Healthy, Wealthy, Wise, and Happy? Assessing Age Differences in Evaluative and Emotional Well-Being Among Mature Adults from Five Low- and Middle-Income Countries
}

\author{
Clémence Kieny $^{1}$ (D) $\cdot$ Gabriela Flores $^{1} \cdot$ Michael Ingenhaag $^{1} \cdot$ Jürgen Maurer $^{1}$
}

Accepted: 5 October 2020 / Published online: 24 October 2020

(c) The Author(s) 2020

\begin{abstract}
This study assesses the relationship between age and two dimensions of subjective wellbeing - evaluative and emotional_-among mature adults from five low-and middle-income countries. We use data from the World Health Organization's Study on Global AGEing and Adult Health to contrast the associations of age with subjective well-being when controlling only for gender with the corresponding partial associations when including a richer set of covariates. Adjusting only for gender, we find negative associations of age with evaluative well-being, while the corresponding age gradients for emotional well-being are relatively flat. By contrast, adjusting for further socio-demographic factors results in positive associations of age with both evaluative and emotional well-being. Oaxaca-Blinder decompositions allow us to explore the roles of two factors to account for any unadjusted age differences in subjective well-being: age-group differences in individual characteristics and life circumstances, and age-specific associations of individual characteristics and life circumstances with subjective well-being. While adverse circumstances such as poor health and low income contribute to lower levels of evaluative well-being among older adults, age per se is-ceteris paribus-positively associated with subjective well-being. Even in poorer countries, older age does not need to be a time of low subjective well-being. Policies aimed at preserving income and limiting or compensating old-age disability appear to be key for maintaining subjective well-being among older adults.
\end{abstract}

Keywords Subjective well-being Evaluative well-being $\cdot$ Emotional well-being $\cdot$ Age differences $\cdot$ Low- and middle-income countries $\cdot$ Decomposition analysis

Clémence Kieny

clemence.kieny@unil.ch

Gabriela Flores

floressg@who.int

Michael Ingenhaag

michael.ingenhaag@gmail.com

Jürgen Maurer

jurgen.maurer@unil.ch

1 University of Lausanne, Internef, Dorigny, 1015 Lausanne, Switzerland 


\section{Introduction}

Individuals' assessments of their own subjective well-being have recently become central inputs to evaluations of social conditions and human development (Dolan et al. 2011; Stiglitz et al. 2009). These measures complement traditional indicators of economic performance and social progress. An important rationale for using subjective well-being as a complementary measure for social progress is the common view that people are arguably the best judges of their own interests, priorities and welfare, and that improving individuals' subjective well-being should thus be a key priority for public policy. Despite remaining concerns regarding the validity of such self-reported subjective well-being measures, there is growing evidence that subjective assessments of individuals' own well-being and psychological/mental state are related to other objective indicators of health and well-being such as biological markers and health outcomes, which has led to increasing confidence in their usefulness as a complementary indicator for measuring social progress (Krueger and Stone 2014).

Subjective well-being comprises at least two conceptually different but related dimensions, namely evaluative and emotional well-being ${ }^{1}$ (Dolan et al. 2017; OECD 2013; Pavot et al. 1991). Evaluative well-being is defined on the basis of individuals' introspective cognitive judgements of their own quality of life, and is typically measured by asking respondents how satisfied or happy they are with their life overall, or with specific life domains such as health or income. Evaluative well-being may also be viewed as the subjective evaluation of objective determinants of well-being such as health or income. Other types of measures - commonly labeled emotional or experienced well-being measuresaim at capturing the quality and intensity of individuals' affective experiences in daily life (OECD 2013; Stone et al. 2013). Emotional well-being may thus be seen as the subjective evaluation of one's own psychological or mental state. Beyond capturing distinct, yet complementary aspects of subjective well-being, evaluative and emotional well-being also differ with respect to their antecedents and consequences (Kahneman and Riis 2005), and thus often show different associations with individual characteristics and life circumstances (Deaton and Stone 2013; Kahneman and Deaton 2010; Kapteyn et al. 2015; Knabe et al. 2010; Stone et al. 2010).

Declining fertility and increased longevity worldwide have made population aging a global phenomenon, and demographic projections suggest that several low- and middleincome countries are likely to age particularly rapidly (United Nations 2017). In this context, it is crucial to understand the link between aging and subjective well-being as well as the drivers of subjective well-being in older populations. While this question has often been studied in high-income countries, there is only limited evidence coming from developing countries. A better understanding of this relationship may provide relevant information to policy-makers in the developing world regarding the targeting of interventions and potential levers for policies to increase the subjective well-being of this growing part of the population.

\footnotetext{
1 In addition to the common distinction between evaluative and emotional well-being, some definitions of subjective well-being also include a "eudaimonic" aspect of subjective well-being. The concept of eudaimonic well-being moves beyond a purely hedonistic vision of what constitutes a "good life" to focus on a person's functioning and realization of her potential, thereby including both capabilities and outcomes such as autonomy, competence, interest in learning, goal orientation, sense of purpose, resilience, social engagement, caring and altruism (Kapteyn et al. 2015).
} 
This paper analyzes the cross-sectional relationship between age and subjective wellbeing during later life using data from the World Health Organization's (WHO) Study on Global AGEing and Adult Health (SAGE) (2007-2010). ${ }^{2}$ In view of the different conceptual bases of evaluative and emotional well-being and their diverse determinants and consequences, we contrast the relationship between age and each facet of subjective wellbeing. This approach allows for a more comprehensive analysis than focusing on one of the two dimensions alone. This is especially important in view of the growing evidence that these two aspects of subjective well-being often show diverging patterns across different population strata (e.g., Hansen and Slagsvold 2012; Kahneman and Deaton 2010; Knabe et al. 2010).

For each measure of the two dimensions of subjective well-being, i.e., evaluative and emotional, we aim to answer four specific questions: (1) Compared to middle-aged individuals, do older individuals experience higher or lower subjective well-being? (2) Do potential age differences in subjective well-being change when individual characteristics and life circumstances such as family status, health or income are taken into consideration? (3) To what extent do these age-related differences in individual characteristics and life circumstances explain potential differences in subjective well-being between older and middleaged persons? (4) Are older adults better or worse than their middle-aged counterparts at maintaining their subjective well-being in the face of challenging life circumstances such as ill health or poverty?

The use of control variables in subjective well-being research has been subject to debate (Blanchflower and Oswald 2008, 2009; Glenn 2009). In this context, we perform both gender-only-adjusted (thereafter referred to as gender-adjusted) comparisons of subjective well-being between different age groups and fully-adjusted regressions of subjective well-being on age that also account for a large set of control variables related to individuals' health status, socio-demographic characteristics and community participation. Genderadjusted results may be most pertinent for policy considerations, as they uncover differences in well-being across age groups which can then be targeted with specific policies (Research Question 1). Fully-adjusted analyses account for potential age-group differences in other individual characteristics and life circumstances that may at least partly mediate the gender-adjusted relationship between age and subjective well-being, and thus isolate the partial association of age with subjective well-being ceteris paribus (Research Question 2).

While subjective well-being differences across age groups may be linked to observable group-specific characteristics, these differences may also in part be due to potential differences in the strength of the relationship that these observable group-specific characteristics display with subjective well-being across different age groups (age interactions). We employ Oaxaca-Blinder decompositions in order to assess whether the relationships between individual characteristics and life circumstances on the one hand, and subjective well-being on the other, differ by age group. This allows to attribute mean age-group differences in subjective well-being to explained (related to group differences in life circumstances and individual characteristics) and unexplained parts. Specifically, we use these decompositions to explore the respective effect on observed age-group differences in subjective well-being of (1) differences in individual characteristics and life circumstances across age groups (Research Question 3) and (2) age-specific associations between

\footnotetext{
${ }^{2}$ Specifically, we use SAGE data on individuals above the age of 50 living in five low- and middle-income countries (China, India, Ghana, Russia and South Africa).
} 
individual characteristics and life circumstances, and subjective well-being (Research Question 4). While our analyses are based on cross-sectional data and thus remain merely descriptive, the above exercise is instructive in highlighting important age-group differences in evaluative and emotional well-being across a range of low- and middle-income countries and in exploring potential pathways that may underlie these differences.

Our study delivers new insights on the association between age and subjective wellbeing among mature adults. Indeed, little is known to date on this topic in the context of developing countries, where two-thirds of the global population live. The evidence is especially scare for emotional well-being, as many studies only focus on evaluative well-being when assessing the relationship between age and subjective well-being in the developing world. To our knowledge - our study presents the most comprehensive overview to date of the relationship between subjective well-being and old age across different developing country contexts. The use of SAGE data allows us to systematically focus on five major low- and middle-income countries across several world regions and at different stages of economic development. Moreover, we are able to contrast two important dimensions of subjective well-being based on data from the same individuals and using the same methodology. Finally, by performing both gender- and fully-adjusted analyses in parallel, our paper contributes to the aforementioned methodological debate regarding the use of control variables in subjective well-being research.

\section{Literature Review}

While a complete review of the large, multidisciplinary body of knowledge on the relationship between age and subjective well-being is beyond the scope of this paper (see, for example, López Ulloa et al. (2013) for a more comprehensive review), we nonetheless present below a short and selective review of the literature on the topic focusing on studies that are most closely related to our own work. This section begins by reviewing the evidence on the relationship between age and evaluative well-being, then between age and emotional well-being. Finally, we discuss the few papers that consider both dimensions together on the same population.

\subsection{Age and Evaluative Well-Being}

Many results from unadjusted models of the relationship between evaluative well-being and age in countries at all income levels suggest that the unadjusted association between age and evaluative well-being might be negative, even if the overall evidence remains mixed. For example-in high-income countries-studies in Taiwan (Chen 2001) and Germany (Schilling 2006) find a decreasing age profile in evaluative well-being. Moreover, Deaton (2008) shows that life satisfaction declines drastically across age groups in middle-income countries, while corresponding decreases are generally smaller in lowincome countries. Yet, when individual characteristics and life circumstances are taken into account, most studies tend to find a U-shaped relationship between age and evaluative well-being throughout life, with the nadir of life satisfaction being reached between the mid-30s and early 50s (e.g. Blanchflower and Oswald 2008). In addition, there appears to be an additional drop in evaluative well-being toward the end of life (e.g. Frijters and Beatton 2012; Gwozdz and Sousa-Poza 2010). While most of the evidence regarding the partial association between age and evaluative well-being is based on data from high-income 
countries, some studies have also explored this relationship in developing country settings, often with less clear-cut findings (e.g. Blanchflower and Oswald 2008; Graham and Ruiz Pozuelo 2017; Powdthavee 2003). The existing evidence regarding our study population is thus inconclusive, adding to the importance of performing a comprehensive analysis of the relationship between age and evaluative well-being in low- and middle-income countries.

\subsection{Age and Emotional Well-Being}

We now turn to the relationship between age and emotional well-being. Using unadjusted models, several studies in high-income countries find that levels of emotional well-being are similar or even higher among older adults compared to their middle-aged counterparts (e.g., Carstensen et al. 2000 in the USA). Other studies (e.g., Carstensen et al. 2011; Dolan et al. 2017; Stone et al. 2010) report a U-shape in emotional well-being with a nadir in the $50 \mathrm{~s}$. We found only few reports in the literature regarding the raw association between age and emotional well-being in developing countries. The 2015 World Happiness Report (Fortin et al. 2015) and Steptoe et al. (2015) analyze by region the evolution over the life course of positive and negative emotions. Their findings largely differ by setting as well as by the specific emotion considered, and thus can only be characterized as mixed. Using adjusted models, several studies report an improvement in emotional well-being with age in older adults (e.g., Carstensen et al. 2011; Dolan et al. 2017; Stone et al. 2010). Stone et al. (2010) find that positive experienced well-being has a U-shaped age profile (reaching its lowest point at 50 years old) while negative experienced well-being decreases with age. This suggests that the net affect is higher in older adults compared to middle-aged individuals. We could not find equivalent studies focusing on developing countries and analyzing the effect of age on emotional well-being while controlling for other factors. The current state of knowledge on the relationship between age and emotional well-being is therefore weak-in particular for developing countries-and sometimes contradictory. Moreover, unlike most existing studies which consider individual emotions separately, our analyses aggregate several emotions into consolidated estimates of overall net affect, therefore resulting in a more integrated representation of individuals' emotional status.

\subsection{Studies Comparing Evaluative and Emotional Well-Being}

Few studies explicitly compare measures of evaluative and emotional well-being based on data from the same individuals. Using cross-sectional data from Norway, Hansen and Slagsvold (2012) find that life satisfaction and negative affect are stable in older age groups while positive affect displays a negative association with age. However, using longitudinal data, they find a decrease in life satisfaction and negative affect with age while positive affect remains stable in old age. Based on USA data, Dolan et al. (2017) and Stone et al. (2010) report U-shaped patterns for both evaluative and emotional measures of well-being, whether or not control variables are included in the analysis. This suggests that older individuals have higher levels of both evaluative and emotional well-being than their middleaged counterparts. Steptoe et al. (2015) observe three kinds of patterns when comparing evaluative and emotional well-being of older individuals to that of their younger counterparts in various regions of the world. First, in countries of the former Soviet Union and Eastern Europe, both evaluative and emotional well-being are strongly negatively associated with age. Second, in Latin America and the Caribbean, evaluative well-being shows a small negative association with age while emotional well-being is either not or slightly 
positively associated with age. Finally, in sub-Saharan Africa, both evaluative and emotional well-being seem rather stable across age groups. It is of note that our study cannot investigate the existence of a U-shape relationship between age and subjective well-being in our countries of interest, as our dataset focuses on adults over the age of 50, and hence on individuals who are older than the age that most commonly corresponds to the lowest point of the documented U-shaped relationships. Based on the scarcity of evidence and the mixed conclusions of the above-mentioned studies, it is difficult to conclude on the potential existence of universal patterns for the association of age, and evaluative and emotional well-being. Moreover, it cannot be ruled out that inconsistent trends across studies may be attributable to the use of different databases or methodological approaches. Our study thus provides a valuable opportunity to assess these relationships comprehensively using information on both the evaluative and emotional well-being of the same persons based on a single database, while comparing different countries, and contrasting partial and total associations.

\section{Data and Measures}

We use data on older adults from five low- and middle-income countries (China, India, Ghana, Russia and South Africa) who participated in the first-and to date only available - wave of the World Health Organization's (WHO) Study on Global AGEing and Adult Health (SAGE), 2007-2010. ${ }^{3}$ Being a general-purpose aging survey, SAGE was designed to be nationally representative for its target population of individuals aged 50 and older in each study site and contains extensive individual—and household-level data about study participants, including information on socio-demographic characteristics, household finances, individuals' health and healthcare use, and social networks. The SAGE survey also includes extensive information on individuals' subjective well-being, covering aspects of both evaluative and emotional well-being. With regard to evaluative well-being, SAGE contains a range of measures of general as well as domain-specific life satisfaction. In addition, SAGE also contains unusually detailed data on individuals' emotional well-being. To this end, SAGE collects data on the frequency of fourteen positive and negative emotion over the previous day as well as an abbreviated version of the Day Reconstruction Method (DRM) of Kahneman et al. (2004), which combines data on time use with measurements of affective experiences through time.

\subsection{Measures}

We analyze two different measures of evaluative well-being: general life satisfactionmeasured on a five-point Likert scale - and a composite quality of life score - the WHO Quality of Life Index (also referred to as EUROHIS-QOL 8 index (Power 2003)) — constructed by summing the scores of individuals' satisfaction in eight different life domains, ${ }^{4}$ each measured on a five-point scale.

\footnotetext{
${ }^{3}$ We focus on five out of the six countries where SAGE data was collected as a large number of missing values in the well-being section of the Mexican data does not allow us to assess our research questions in Mexico.

4 (1) Overall quality of life; (2) Health; (3) Energy for everyday life; (4) Ability to perform activities of daily living; (5) Themselves; (6) Personal relationships; (7) Ability to meet personal needs; and (8) Conditions of living place.
} 
We also use two distinct strategies to measure emotional well-being. First, we construct an emotion score based on a set of questions asking respondents to report whether they experienced eleven negative and three positive emotions ${ }^{5}$ during much of the day preceding the interview. The emotion score represents the number of self-reported positive emotions minus the corresponding number of negative emotions. The second measure of emotional well-being, experienced utility, is a time-weighted evaluation of affective experiences over the previous day. To construct this measure, we use data from SAGE's abbreviated DRM, which contains respondents' report of ten successive activities (from a list of 22 options) following a randomly assigned start time of the previous day (either morning, afternoon, or evening). Participants report the duration of each activity as well as the occurrence and strength of five negative and two positive emotions ${ }^{6}$ on a three-point scale. Due to the large number of potential activity types, some of the 22 activities are reported with low frequencies. In order to simplify econometric estimation, we thus follow previous research (Flores et al. 2015, 2020; Kieny et al. 2020) and reclassify the 22 activities into five activity groups-work, housework, travel, leisure, and self-care. As proposed by Kahneman and Krueger (2006), we construct a measure of respondent $i$ 's net affect during activity group $a$, as:

$$
u_{i, a}=\sum_{s}\left(\sum_{l} h_{i s} P A_{i s}^{l}-\sum_{k} h_{i s} N A_{i s}^{k}\right) \forall a=1, \ldots, 5
$$

where $P A_{i s}^{l}$ is the $l$ 'th positive affect and $N A_{i s}^{k}$ is the $k^{\prime}$ th negative affect reported by individual $i$.

In order to control for respondents potentially reporting multiple episodes of the same activity group, we compute time-weighted average of positive and negative affect scores associated with each activity group episode $s$, where the weight is computed as $h_{i s}=\frac{t_{i s}}{T_{i a}}$, with $t_{i s}$ representing the duration of one specific episode $s$ of activity $a$, and $T_{i a}$ the overall time spent on activity group $a$ during the randomly assigned time period. The net affect of an activity group $a$ thus represents the sum of net affects over all episodes of activity group $a$ in the previous day, weighted by the proportion of time spent in each episode $s$ relative to the total time spent on activity group $a$. Aggregating positive and negative affects in this simple way assumes cardinal net affects as well as a time-separable inter-temporally additive utility function. Using these calculations, our measure of experienced utility is then defined as:

$U_{i}=\sum_{a} \tau_{i a} u_{i a}$, with $\tau_{i a}=\frac{T_{i a}}{T_{i}}$ representing the percentage of non-sleeping time $T_{i a}$ spent on activity group $a$ by individual $i$, relative to $T_{i}$, i.e., the total time covered by the 10 successive activities reported, and $u_{i, a}$ representing respondent $i$ 's net affect during activity group $a$ as defined above. Non-sleeping time is unequally distributed across morning, afternoon and evening groups of the abbreviated DRM. Thus, in order to ensure comparability of results across DRM groups with different starting times, we use time shares rather than absolute activity group durations as weighting factors.

\footnotetext{
${ }^{5}$ Negative: Feeling worried, rushed, irritated, depressed, tense/stressed, lone/bored, physical pain, sleepiness, stomach ache, headache; Positive: Feeling calm, relaxed, and smiling or laughing.

${ }^{6}$ Negative: Feeling worried, rushed, irritated or angry, depressed, tense or stressed; Positive: Feeling calm or relaxed, and feeling enjoyment.
} 
All measures of subjective well-being are standardized at the country level such that estimated differences ought to be interpreted in country-specific standard deviation units of the respective outcome. Thereafter, the four measures of subjective well-being will be referred to as life satisfaction, WHOQOL-8 score, emotion score and experienced utility.

\section{Methodology}

There is evidence that well-being measures are strongly influenced by cultural background (e.g. Diener et al. 2003). We therefore estimate all regressions on the full sample (pooled models) — while including binary variables to control for country differences in intercepts-as well as on each country's subsample (country-specific models). This setting allows us to check the robustness of our findings across countries.

\subsection{Statistical Analyses}

To answer the first research question and document potential differences in subjective wellbeing across age groups, we estimate so-called gender-adjusted models using ordinary least squares regressions for each of the four subjective well-being outcomes. Specifically, we estimate gender-adjusted models of the form:

$$
S W B_{i}=\alpha_{G}+\text { Age }_{i} \beta_{G}+\gamma_{G} \text { Female }_{i}+\text { Country }_{i} \theta_{G}+\varepsilon_{i} \text { in the pooled regressions }
$$

and

$$
S W B_{i}=\alpha_{G}+\text { Age }_{i} \beta_{G}+\gamma_{G} \text { Female }_{i}+\varepsilon_{i} \text { in the country-specific regressions }
$$

whereby $S W B_{i}$ denotes each different measure of subjective well-being for respondent $i, A g e_{i}$ denotes a set of ten-year age dummies (60-69, 70-79, and 80 or more) indicating respondent $i$ 's age group, Female $_{i}$ denotes an indicator for respondent $i$ 's gender, and Country $_{i}$ represents the vector of country dummies. The $G$ subscripts stand for gender-adjusted.

We then move to estimates of the partial association of age with subjective well-being holding other life circumstances fixed-the ceteris paribus analysis aimed at answering the second research question: Keeping personal characteristics and life circumstances fixed, do older adults report higher or lower levels of subjective well-being than middleaged individuals? To this end, we expand the above statistical analysis of well-being to also incorporate additional covariate information $X_{i}$ related to respondents' personal characteristics and life circumstances. ${ }^{7}$ The inclusion of control variables allows us to identify and quantify potential mechanisms or confounders in the relationship between gender and experienced well-being, as well as to identify the remaining partial association of age once

\footnotetext{
7 Fully-adjusted models include a large set of additional control variables such as respondents' sociodemographic and economic status, health status and social cohesion. Socio-demographic characteristics and economic status variables include the following: age, place of residence (urban or rural), employment status, household permanent income quartiles, education level, marital status, and composition of the household (number of adults and children). Health status variables include the 12-item WHO disability index and a measure of self-assessed pain. Controls for social cohesion include measures of community involvement, trust in others (neighbors, co-workers or strangers) as well as indicators for respondents' feeling safe in their neighborhood and for having suffered a violent crime during the past 12 months..
} 
these mediators are taken into account. A guiding principle to estimate the remaining partial association of age with subjective well-being is to include control variables that affect subjective well-being and are also correlated to age. We thus selected control variables available in our dataset that are significantly correlated with age in at least a subset of study countries (Table 1), and that we suspected to be related to subjective well-being. We provide below literature citations for a subset of these variables as illustration. For example, it was shown that household composition has strong implications for emotional health in older adults (e.g. Chen and Short 2008). Similarly, results by Helliwell and Wang (2011) reveal strong linkages between several trust measures and subjective well-being. Finally, it is well-established that married individuals generally have higher subjective well-being compared to the never-married, divorced, or widowed (e.g. Mastekaasa 1993), and evidence suggests that employed individuals have higher evaluative well-being but similar emotional well-being compared to the unemployed (Knabe et al. 2010). These fullyadjusted models take the form:

$$
S W B_{i}=\alpha_{F}+\operatorname{Age}_{i} \beta_{F}+X_{i} \delta_{F}+\text { Country }_{i} \theta_{F}+\epsilon_{i} \text { in the pooled regressions }
$$

and

$$
S W B_{i}=\alpha_{F}+A g e_{i} \beta_{F}+X_{i} \delta_{F}+\epsilon_{i} \text { in the country-specific regressions }
$$

whereby $X_{i}$ includes the Female dummy as well as the whole set of control variables listed above. The $F$ subscripts stand for fully-adjusted.

To answer Research Questions 3-To what extent do differences in individual characteristics and life circumstances explain potential differences in subjective well-being between older and middle-aged persons?-and 4-Are older adults better or worse than their middle-aged counterparts at maintaining their subjective well-being in the face of challenging life circumstances such as ill health or poverty?-we decompose any genderadjusted age-group differences in subjective well-being between individuals aged 50-64 (which we call "Middle aged") and persons aged 65 and older (which we call "Older") using a Oaxaca-Blinder decomposition framework. Specifically, we estimate separate OLS regressions for the whole population as well as for each age group:

$$
\begin{gathered}
S W B_{i}=z_{i}^{\prime} \beta^{\text {Total }}+\varepsilon_{i}^{\text {Total }} \\
S W B_{i}=z_{i}^{\prime} \beta^{\text {Older }}+\varepsilon_{i}^{\text {Older }} \text { if } \text { Age }_{i} \geq 65 \\
S W B_{i}=z_{i}^{\prime} \beta^{\text {Middle }}+\varepsilon_{i}^{\text {Middle }} \text { if } 50 \leq \text { Age }_{i} \leq 64
\end{gathered}
$$

where the vectors of $\beta$ parameters include intercepts and $z_{i}$ refers to the vector of all explanatory variables, including gender. Moreover, $z_{i}$ includes country dummies in pooled sample regressions. We use the corresponding estimation results to decompose overall group differences in subjective well-being into so-called explained and unexplained parts as described by Neumark (1988): 


$$
\begin{gathered}
\Delta=\overline{S W B}^{\text {Middle }}-\overline{S W B} \text { Older } \\
=\bar{z}^{\text {Middle }} \beta^{\text {Middle }}-\bar{z}^{\text {Older }} \beta^{\text {Older }} \\
=\underbrace{\left(\bar{z}^{\text {Middle }}-\bar{z}^{\text {Older }}\right)^{\prime} \beta^{\text {Total }}}_{\text {Explained }}+\underbrace{\left[\bar{z}^{\text {Middle }}\left(\beta^{\text {Middle }}-\beta^{\text {Total }}\right)+\bar{z}^{\text {Older }}\left(\beta^{\text {Total }}-\beta^{\text {Middle }}\right)\right]}_{\text {Unexplained }}
\end{gathered}
$$

where $\beta^{\text {Total }}$ is the vector of coefficients from the regression using the whole population, and $\bar{z}$ refers to the vector of sample averages of explanatory variables. The explained part captures the difference in subjective well-being between older and middle-aged individuals which is attributable to the differences in average individual characteristics and life circumstances across the two age groups. The unexplained part, in turn, corresponds to the difference in subjective well-being that is attributable either to (a) differences in the relationships between subjective well-being and individual characteristics and life circumstances across the two age groups (as alluded to by Research Question 4 concerning potential age-related differences in resilience) or (b) entirely unobserved factors underlying different levels of subjective well-being across the two age groups, that are captured by differences in the intercepts of the two age-group-specific regression models.

Analyses of all four outcome variables rely on linear specifications. While WHOQOL- 8 score, emotion score and experienced utility are (close to) continuous, life satisfaction is an ordinal variable which could also be analyzed in the context of an ordered response model. However, Ferrer-i-Carbonell and Frijters (2004) show that ordinal and cardinal use of life satisfaction measures often give similar results in practice. We thus treat all outcome variables as continuous to ensure comparability of our results across measures and sidestep potential issues related to the general lack of nonparametric identification of group differences in ordered outcome measures (Bond and Lang 2019). ${ }^{8}$

\section{Descriptive Statistics}

Table 1 presents overall and country-specific sample means for all variables used in our analysis both for the full samples and by age group. We also show the age-group-specific means for "middle-aged" respondents aged 50-64 years and "older" respondents aged 65 and older, separately, as these represent important components of our subsequent decomposition analysis.

Table 1 demonstrates that our middle-aged and older samples are significantly different in terms of several characteristics. The proportion of women is significantly higher in the older sample in China, Russia, and South Africa, but not so in Ghana and India. In addition, older respondents are generally less likely to (still) be married, are less educated, and tend to work less often than their middle-aged counterparts. With the exception of India and South Africa, older adults also tend to have lower income. Finally, compared to middle-aged individuals, respondents aged 65 and older report higher levels of disability and pain.

\footnotetext{
${ }^{8}$ Moreover, we performed robustness analyses based on parametric ordered probit models for the life satisfaction measure, which resulted in qualitatively similar findings.
} 


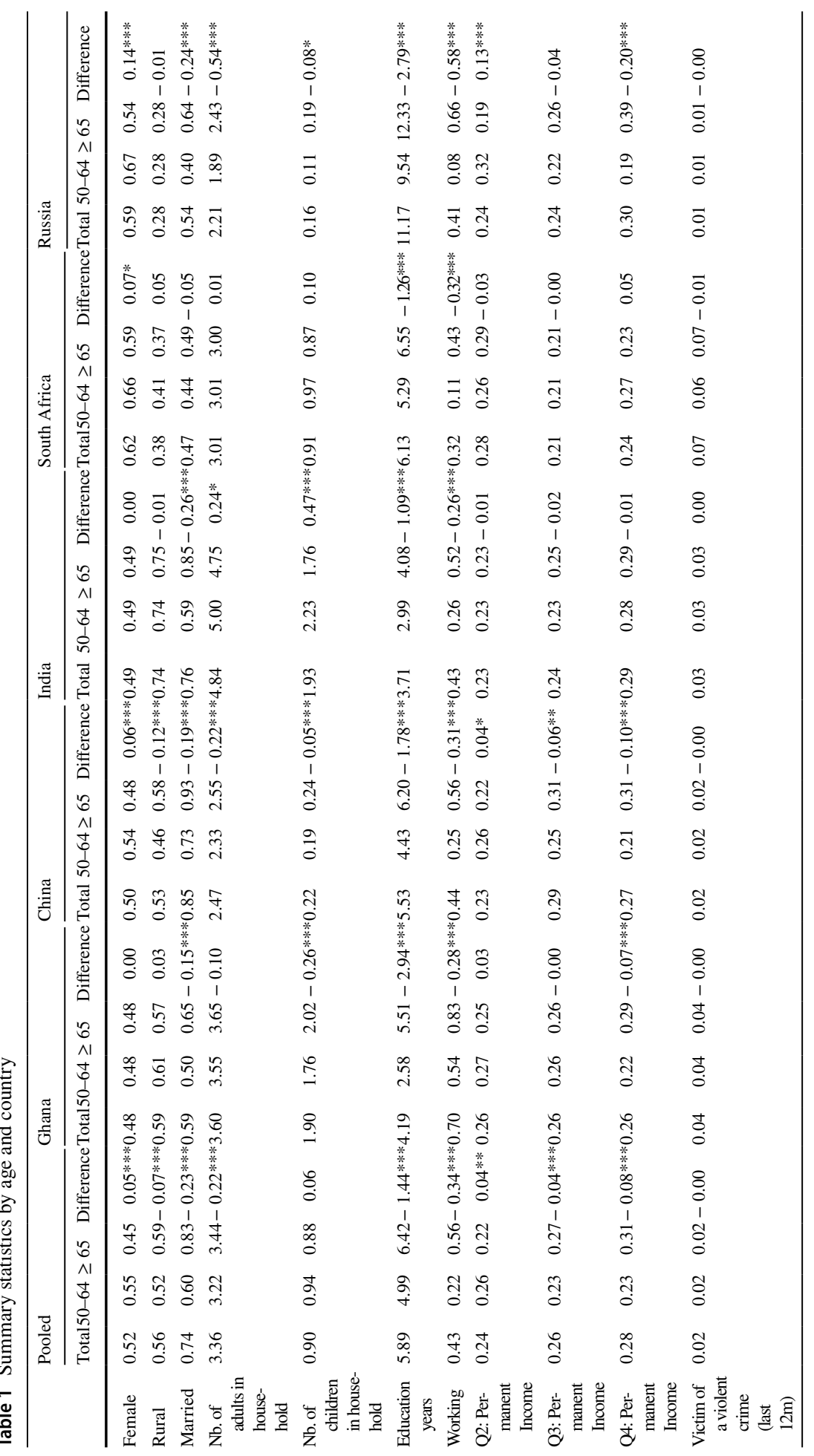




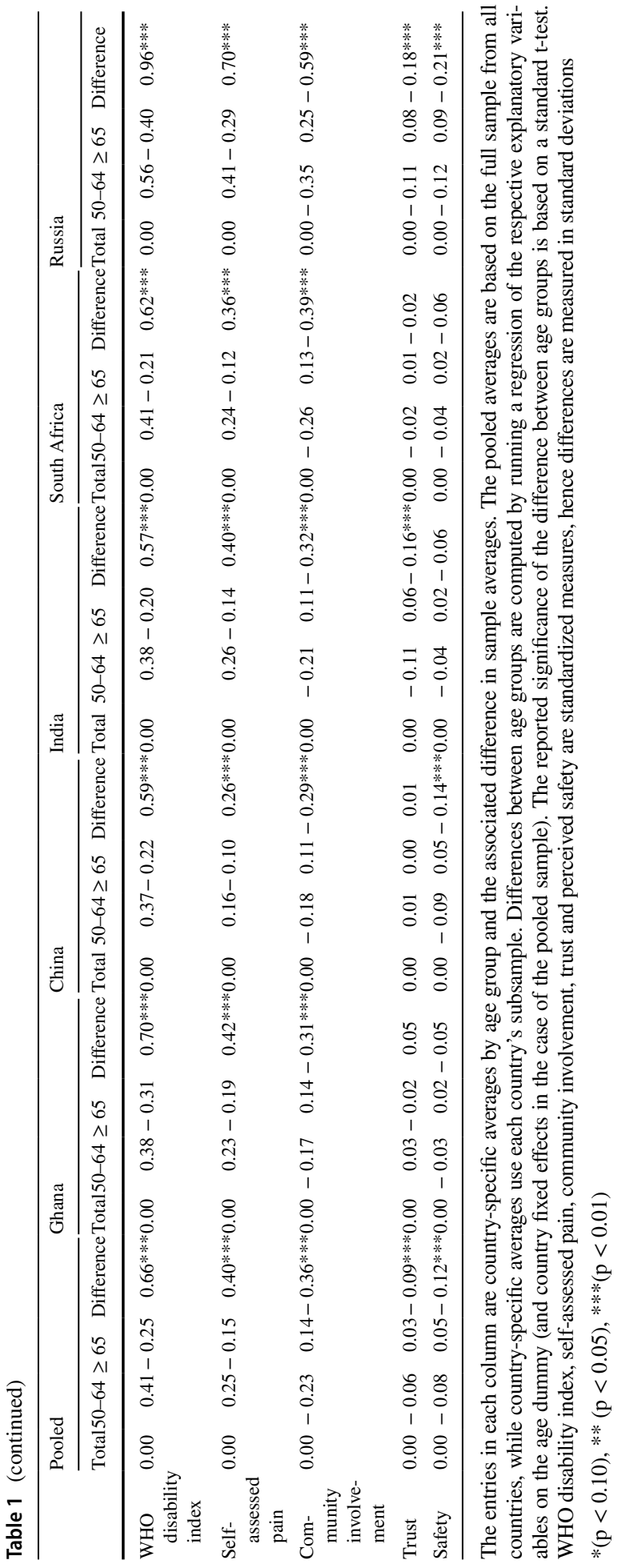




\section{Results}

Figure 1 contrasts the partial associations of age with our two measures of evaluative wellbeing, life satisfaction and the WHOQOL-8 score, in the gender-adjusted models (dark grey) and fully-adjusted models (light grey), respectively. The estimation results from our gender-adjusted models using the pooled data from all countries show that-adjusting for gender and country only-evaluative well-being is lower in older age groups than in middle-aged adults. Similar results are also consistently found in separate gender-adjusted regressions by country. By contrast, once we incorporate a richer set of individual characteristics and life circumstances into our fully-adjusted models, the remaining partial associations of age with evaluative well-being increase considerably relative to those from the gender-adjusted models, often turning from negative to positive partial associations.

Figure 2 presents analogous estimates for the partial associations between age and our two measures of emotional well-being, the emotion score and our DRM-based measure of experienced utility. Compared to evaluative well-being, the gender-adjusted models suggest that the emotion score is more stable across age groups, with generally much smaller coefficient estimates which are also often not statistically significantly different from zero. Moreover, we observe somewhat different age patterns depending on the country. In Ghana and Russia, older age groups report slightly lower emotion scores, while in India and China we observe no significant differences between older age groups and their middleaged counterparts. In South Africa, older age groups tend to have higher average emotion

\section{Evaluative Well-being \\ Gender-adjusted vs. Fully-adjusted}

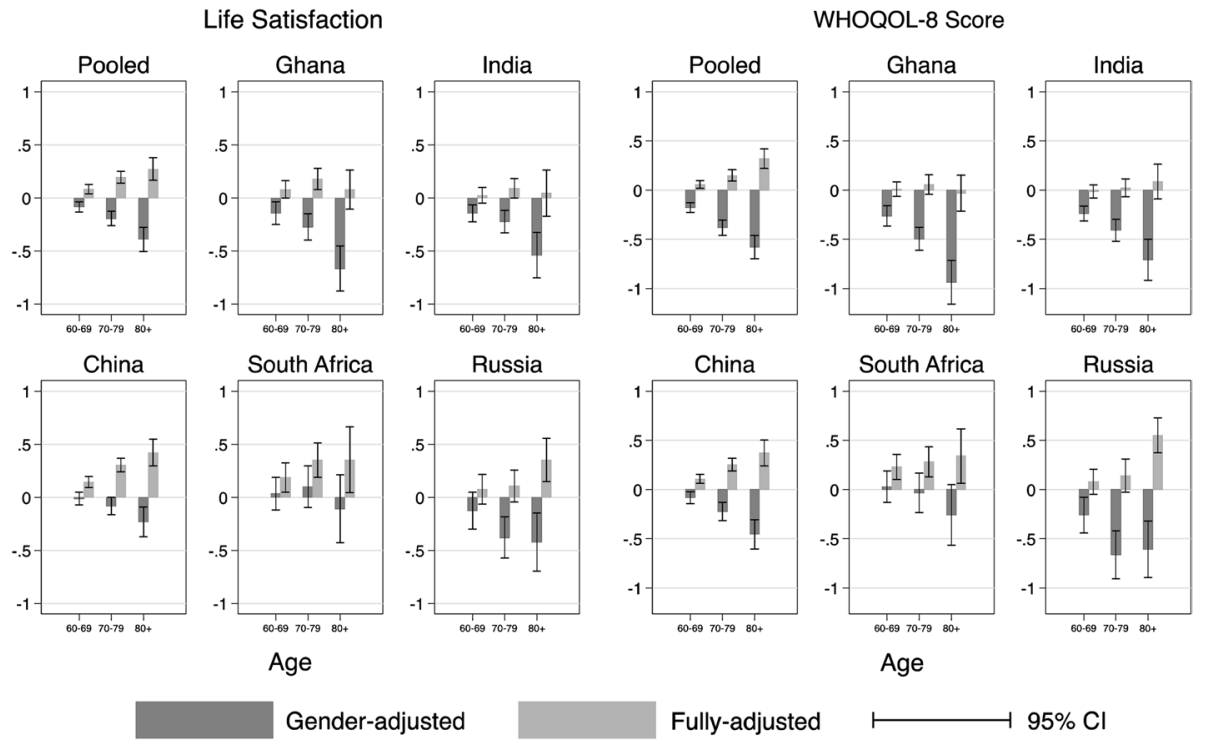

Fig. 1 Partial associations between age and the two measures of evaluative well-being (life satisfaction and WHOQOL-8 score) for the pooled sample and each country individually. Each coefficient is represented by a box and a $95 \%$ confidence interval. The dark boxes represent the age coefficients of gender-adjusted regressions while the light boxes represent the age coefficients of the fully-adjusted regressions 
Emotional Well-being

Gender-adjusted vs. Fully-adjusted

Emotion Score

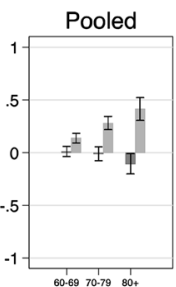

China
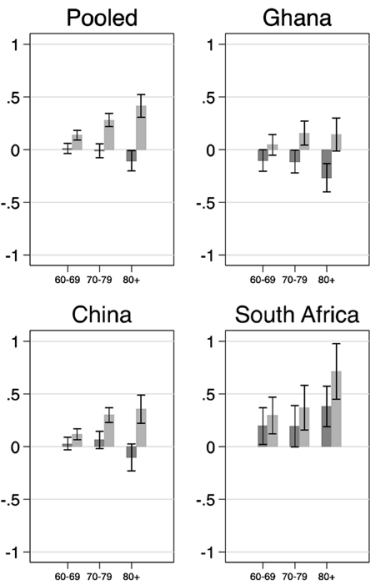

South Africa

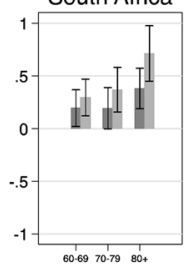

Age
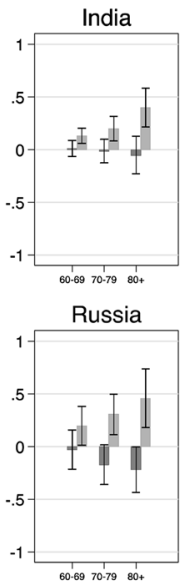

Gender-adjusted
Experienced Utility
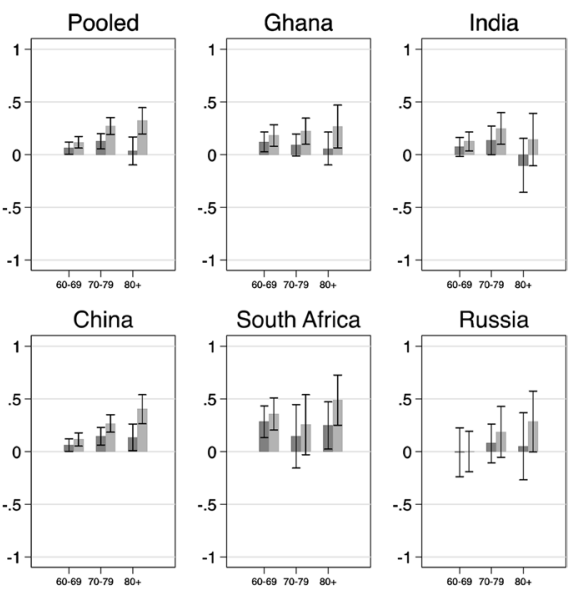

Age

Fully-adjusted

$95 \% \mathrm{Cl}$

Fig. 2 Partial associations between age and the two measures of emotional well-being (emotion score and experienced utility) for the pooled sample and each country individually. Each coefficient is represented by a box and a $95 \%$ confidence interval. The dark boxes represent the age coefficients of gender-adjusted regressions while the light boxes represent the age coefficients of the fully-adjusted regressions

scores, especially individuals in the oldest age category (80 and over). Experienced utility also appears largely stable across age groups in gender-adjusted models. If anything, it appears that older age groups tend to have slightly higher levels of experienced utility than their middle-aged counterparts. However, as in the case of evaluative well-being, the partial associations with age and emotional well-being increase considerably once additional measures of individual characteristics and life circumstances are included into the statistical analyses. Ceteris paribus, emotional well-being thus seems generally higher among older age groups compared to middle-aged individuals.

Tables 6, 7, 8 and 9 in "Appendix" present the detailed results of the gender- and fully-adjusted regressions summarized in Figs. 1 and 2. Only covariates with consistently significant associations with any of our four subjective well-being outcomes will be discussed below.

Tables 6 and 7 in "Appendix" present results from the gender-adjusted (Panel A) and fully-adjusted (Panel B) regressions for evaluative well-being. We observe that belonging to the highest income quartile is very strongly positively associated with both life satisfaction and the WHOQOL-8 score. Moreover, higher levels of disability and selfassessed pain are strongly associated with lower levels of evaluative well-being for both measures. In addition, working is positively associated with life satisfaction in Ghana and China, and with the WHOQOL-8 score everywhere but in Russia. Finally, our social cohesion variables-community involvement, trust in others, and feeling of safety in one's neighborhood—are all positively associated with evaluative well-being. 
Tables 8 and 9 in "Appendix" show the details of the gender-adjusted (Panel A) and fully-adjusted (Panel B) models for our two measures of emotional well-being. As for evaluative well-being, we observe that income and health status display the strongest partial associations with emotional well-being. The relationship between emotional well-being and social cohesion variables is inconsistent across measures and countries: while community involvement and trust in others is generally positively associated with the emotion score, only feeling safe in one's neighborhood is consistently positively associated with both the emotion score and experienced utility. In contrast to our findings for evaluative well-being, we see either no association or a negative association between working and emotional well-being, with Ghana being the only exception.

We then investigate to what extent differences in the above individual characteristics and life circumstances may explain differences in evaluative and emotional subjective wellbeing between middle-aged and older persons in the pooled sample as well as in each of our study sites. In addition, we explore how the partial associations between individual characteristics and life circumstances, and subjective well-being differ across age groups. This may point to potential age differences in resilience to different life challenges. Tables 2 and 3 summarize the results of Oaxaca-Blinder decompositions of unadjusted mean age-group differences in evaluative well-being (i.e., Life satisfaction and WHOQOL-8 score) while Tables 4 and 5 present corresponding decomposition results for our measures of emotional well-being (i.e., Emotion score and experienced utility).

The decomposition results for life satisfaction in Table 2 show that the explained parts of the age-group differences generally exceed the observed age-group differences in this measure of evaluative well-being. This finding indicates that-based on differences in individual characteristics and life circumstances alone-one would expect a larger disadvantage of older persons compared to their middle-aged counterparts than the one that is actually observed. Looking in more detail at the specific contributions of various individual characteristics and life circumstances, it appears that age differences in health (as measured by the WHO disability index and self-assessed pain) are the main drivers of explained age-group differences in life satisfaction. The fact that the older age group has a lower proportion of individuals belonging the highest quartile of household income distribution (as shown in Table 1) also contributes significantly to the explained age-group differences in life satisfaction in Ghana, China and Russia. Finally, age-group differences in community involvement also contribute to the explained age-group differences in life satisfaction, albeit to a much smaller extent.

The unexplained parts of the age-group differences in life satisfaction are negative in all countries, even though they are not statistically significant in India and Russia. Furthermore, the unexplained parts of the decompositions are of considerably smaller magnitude than the explained parts, thus partially compensating the overprediction of the age-group differences in well-being based on differences in individual characteristics and life circumstances alone. Looking at the unexplained parts in greater detail does not reveal systematic age-group-specific heterogeneity in the association between individual characteristics and life circumstances on the one hand and life satisfaction on the other, thereby providing little suggestion of potential age-related differences in resilience to life challenges. Moreover, age-group differences in the specific association of individual characteristics and life circumstances with life satisfaction are generally statistically insignificant and inconsistent across study sites.

The corresponding decomposition results for mean age-group differences in the $\mathrm{WHO}$ QOL-8 score reported in Table 3 largely confirm the above findings for life satisfaction as a measure of evaluative well-being. If anything, the previously observed patterns tend to 
Table 2 Decomposition analysis of life satisfaction by country

\begin{tabular}{|c|c|c|c|c|c|c|}
\hline & Pooled & Ghana & India & China & South Africa & Russia \\
\hline $50-64$ & $0.07 * * *$ & $0.13 * * *$ & $0.09 * * *$ & $0.03 *$ & 0.03 & $0.14 *$ \\
\hline$\geq 65$ & $-0.13 * * *$ & $-0.15 * * *$ & $-0.17 * * *$ & $-0.05 * *$ & -0.05 & $-0.19 * *$ \\
\hline Difference & $0.20 * * *$ & $0.28 * * *$ & $0.26 * * *$ & $0.09 * * *$ & 0.08 & $0.32 * * *$ \\
\hline Explained & $0.30 * * *$ & $0.39 * * *$ & $0.29 * * *$ & $0.25 * * *$ & $0.23 * * *$ & $0.39 * * *$ \\
\hline Unexplained & $-0.10 * * *$ & $-0.11 * * *$ & -0.03 & $-0.16^{* * *}$ & $-0.15 * *$ & -0.06 \\
\hline \multicolumn{7}{|c|}{ Panel A. Explained differences } \\
\hline Female & -0.00 & -0.00 & -0.00 & -0.00 & -0.01 & 0.00 \\
\hline Rural & 0.00 & 0.00 & 0.00 & -0.01 & 0.00 & 0.00 \\
\hline Married & -0.01 & $0.02 * *$ & -0.01 & 0.00 & 0.01 & -0.02 \\
\hline $\mathrm{Nb}$ of adults in household & -0.00 & -0.00 & -0.00 & $-0.01 * *$ & -0.00 & -0.02 \\
\hline $\mathrm{Nb}$ of children in household & 0.00 & -0.00 & -0.00 & -0.00 & 0.00 & -0.01 \\
\hline Education years & -0.00 & -0.00 & 0.01 & $-0.01 *$ & -0.01 & $-0.05^{*}$ \\
\hline Working & -0.01 & 0.02 & 0.00 & $0.02 *$ & 0.01 & -0.09 \\
\hline Q2: Permanent Income & $-0.01 * *$ & -0.00 & 0.00 & $-0.01 * * *$ & 0.01 & -0.02 \\
\hline Q3: Permanent Income & $0.01 * *$ & 0.00 & 0.00 & $0.02 * * *$ & 0.00 & 0.00 \\
\hline Q4: Permanent Income & $0.03 * * *$ & $0.03 * * *$ & 0.00 & $0.05 * * *$ & -0.03 & $0.08 * *$ \\
\hline Victim & -0.00 & -0.00 & 0.00 & -0.00 & 0.00 & -0.00 \\
\hline WHO disability index & $0.19 * * *$ & $0.28 * * *$ & $0.22 * * *$ & $0.13 * * *$ & $0.21 * * *$ & $0.30 * * *$ \\
\hline Self-assessed pain & $0.05 * * *$ & $0.04 * * *$ & $0.03 * *$ & $0.04 * * *$ & $0.04 *$ & $0.10 * *$ \\
\hline Community involvement & $0.02 * * *$ & 0.01 & $0.03 * * *$ & $0.01 * * *$ & -0.02 & $0.07 *$ \\
\hline Trust & $0.01 * *$ & -0.00 & $0.01 *$ & -0.00 & 0.00 & 0.02 \\
\hline Safety & $0.01 * * *$ & 0.00 & 0.00 & $0.02 * * *$ & 0.01 & $0.03 *$ \\
\hline \multicolumn{7}{|c|}{ Panel B. Unexplained differences } \\
\hline Female & -0.01 & 0.02 & -0.00 & -0.00 & -0.03 & 0.02 \\
\hline Rural & -0.02 & 0.03 & -0.12 & 0.02 & 0.02 & -0.03 \\
\hline Married & 0.03 & -0.03 & -0.00 & $0.14^{*}$ & 0.07 & 0.03 \\
\hline $\mathrm{Nb}$ of adults in household & -0.03 & 0.06 & -0.02 & -0.01 & -0.10 & -0.13 \\
\hline $\mathrm{Nb}$ of children in household & -0.00 & 0.05 & 0.00 & 0.02 & -0.03 & -0.00 \\
\hline Education years & -0.01 & 0.05 & -0.03 & 0.01 & 0.02 & -0.08 \\
\hline Working & 0.01 & 0.08 & 0.02 & -0.01 & 0.04 & 0.02 \\
\hline Q2: Permanent Income & -0.01 & -0.02 & -0.01 & -0.02 & -0.02 & 0.01 \\
\hline Q3: Permanent Income & -0.01 & -0.03 & -0.03 & 0.03 & -0.06 & -0.05 \\
\hline Q4: Permanent Income & -0.03 & $-0.06^{*}$ & -0.02 & -0.02 & -0.07 & -0.04 \\
\hline Victim & -0.00 & 0.01 & -0.00 & 0.00 & -0.01 & -0.00 \\
\hline WHO disability index & $0.01^{*}$ & $0.01^{*}$ & -0.00 & $0.01 * * *$ & 0.02 & -0.00 \\
\hline Self-assessed pain & 0.00 & -0.00 & 0.00 & -0.00 & -0.01 & 0.00 \\
\hline Community involvement & 0.00 & 0.00 & -0.00 & 0.00 & -0.00 & 0.02 \\
\hline Trust & -0.00 & -0.00 & 0.00 & 0.00 & -0.00 & -0.00 \\
\hline Safety & -0.00 & -0.00 & -0.00 & -0.00 & 0.00 & -0.00 \\
\hline Constant & -0.11 & -0.29 & 0.19 & $-0.34 * *$ & 0.01 & 0.17 \\
\hline Observations & 21,478 & 3026 & 4832 & 8996 & 1999 & 2625 \\
\hline
\end{tabular}

The entries in each column are country-specific partial effects. Reported differences are measured in standard deviation units of each respective outcome of interest, whereby the standardization is performed at the country level. The pooled regression includes country fixed effects

$* p<0.10 ; * * p<0.05 ; * * * p<0.01$ 
Table 3 Decomposition analysis of WHOQOL-8 Score by country

\begin{tabular}{|c|c|c|c|c|c|c|}
\hline & Pooled & Ghana & India & China & South Africa & Russia \\
\hline $50-64$ & $0.13 * * *$ & $0.21 * * *$ & $0.14 * * *$ & $0.08 * * *$ & 0.06 & $0.23 * * *$ \\
\hline$\geq 65$ & $-0.22 * * *$ & $-0.26^{* * *}$ & $-0.27 * * *$ & $-0.13 * * *$ & -0.11 & $-0.32 * * *$ \\
\hline Difference & $0.36^{* * *}$ & $0.47 * * *$ & $0.41 * * *$ & $0.22 * * *$ & $0.17 *$ & $0.55 * * *$ \\
\hline Explained & $0.44 * * *$ & $0.51 * * *$ & $0.41 * * *$ & $0.34 * * *$ & $0.31 * * *$ & $0.64 * * *$ \\
\hline Unexplained & $-0.08 * * *$ & -0.04 & 0.00 & $-0.12 * * *$ & $-0.14 * *$ & $-0.09 *$ \\
\hline \multicolumn{7}{|c|}{ Panel A. Explained differences } \\
\hline Female & $-0.00 *$ & -0.00 & -0.00 & -0.00 & -0.01 & 0.01 \\
\hline Rural & -0.00 & 0.00 & 0.00 & $-0.01 * * *$ & 0.00 & 0.00 \\
\hline Married & 0.01 & 0.01 & 0.02 & 0.00 & 0.01 & 0.02 \\
\hline $\mathrm{Nb}$ of adults in household & -0.00 & -0.00 & -0.00 & $-0.01 * * *$ & 0.00 & $-0.05 * *$ \\
\hline $\mathrm{Nb}$ of children in household & -0.00 & -0.00 & $-0.01 *$ & 0.00 & 0.00 & -0.00 \\
\hline Education years & 0.01 & $0.02 *$ & $0.01 *$ & -0.00 & 0.00 & -0.01 \\
\hline Working & $0.02 * *$ & $0.05 * * *$ & $0.02 *$ & $0.04 * * *$ & 0.03 & 0.02 \\
\hline Q2: Permanent Income & $-0.01 * *$ & -0.00 & 0.00 & $-0.01 * * *$ & 0.01 & -0.03 \\
\hline Q3: Permanent Income & $0.01 * *$ & 0.00 & 0.01 & $0.02 * * *$ & 0.00 & 0.00 \\
\hline Q4: Permanent Income & $0.04 * * *$ & $0.04 * * *$ & 0.01 & $0.05 * * *$ & -0.04 & $0.07 *$ \\
\hline Victim & -0.00 & -0.00 & -0.00 & -0.00 & 0.00 & -0.00 \\
\hline WHO disability index & $0.24 * * *$ & $0.32 * * *$ & $0.25 * * *$ & $0.18 * * *$ & $0.20 * * *$ & $0.36 * * *$ \\
\hline Self-assessed pain & $0.07 * * *$ & $0.05 * * *$ & $0.05 * * *$ & $0.05 * * *$ & $0.07 * * *$ & $0.16 * * *$ \\
\hline Community involvement & $0.02 * * *$ & $0.02 * * *$ & $0.03 * * *$ & $0.02 * * *$ & 0.01 & 0.04 \\
\hline Trust & $0.01 * *$ & -0.00 & $0.01 * *$ & -0.00 & -0.00 & 0.02 \\
\hline Safety & $0.01 * * *$ & 0.00 & 0.00 & $0.02 * * *$ & 0.01 & $0.03 *$ \\
\hline \multicolumn{7}{|c|}{ Panel B. Unexplained differences } \\
\hline Female & -0.00 & -0.02 & -0.03 & 0.01 & -0.05 & 0.01 \\
\hline Rural & 0.03 & 0.00 & -0.05 & 0.06 & 0.00 & 0.02 \\
\hline Married & 0.03 & -0.07 & 0.06 & $0.15^{* *}$ & -0.02 & -0.01 \\
\hline $\mathrm{Nb}$ of adults in household & $-0.08 *$ & $0.11 *$ & -0.07 & $-0.13 * *$ & -0.04 & -0.15 \\
\hline $\mathrm{Nb}$ of children in household & 0.00 & 0.01 & 0.00 & $0.02 *$ & -0.05 & 0.00 \\
\hline Education years & 0.01 & 0.02 & -0.02 & 0.03 & 0.03 & 0.05 \\
\hline Working & 0.01 & $0.13 *$ & 0.00 & -0.02 & 0.04 & 0.04 \\
\hline Q2: Permanent Income & -0.01 & -0.04 & 0.00 & -0.00 & -0.02 & -0.00 \\
\hline Q3: Permanent Income & 0.00 & -0.03 & 0.01 & 0.02 & -0.05 & -0.04 \\
\hline Q4: Permanent Income & -0.00 & $-0.09 * *$ & 0.00 & -0.02 & -0.07 & 0.01 \\
\hline Victim & -0.00 & 0.01 & 0.00 & -0.00 & 0.00 & -0.00 \\
\hline WHO disability index & 0.00 & 0.00 & -0.00 & $0.01 * * *$ & 0.01 & 0.02 \\
\hline Self-assessed pain & -0.00 & -0.00 & -0.00 & $-0.00 *$ & -0.01 & 0.00 \\
\hline Community involvement & $0.01 *$ & 0.00 & $0.01 *$ & 0.00 & -0.00 & 0.02 \\
\hline Trust & -0.00 & -0.00 & -0.00 & 0.00 & -0.00 & -0.00 \\
\hline Safety & -0.00 & -0.00 & 0.00 & -0.00 & 0.00 & -0.00 \\
\hline Constant & $-0.20 * *$ & -0.09 & 0.08 & $-0.23^{*}$ & 0.08 & -0.04 \\
\hline Observations & 21,478 & 3026 & 4832 & 8996 & 1999 & 2625 \\
\hline
\end{tabular}

The entries in each column are country-specific partial effects. Reported differences are measured in standard deviation units of each respective outcome of interest, whereby the standardization is performed at the country level. The pooled regression includes country fixed effects

$* p<0.10 ; * * p<0.05 ; * * * p<0.01$ 
emerge somewhat more strongly, possibly thanks to the more fine-grained measurement of evaluative well-being in the WHOQOL-8 score. Moreover, compared to the previous decompositions based on life satisfaction, work status appears to be an additional contributing factor to age-related differences in evaluative well-being, as working tends to be associated with higher quality of life scores and with younger age (cf. Table 1).

Table 4 shows the decomposition results for emotional well-being as measured by our emotion score. As already highlighted in Fig. 1, age-group differences in emotion scores are relatively small and inconsistent across study sites. Compared to middle-aged respondents, older individuals report slightly lower emotion scores in Ghana and Russia only. Interestingly, all predicted age-group differences in emotion scores, i.e., the explained part of the Oaxaca-Blinder decompositions, indicate an expected disadvantage of older persons based on observed age-group differences in individual characteristics and life circumstances alone. More specifically, the model would generally predict lower levels of emotion scores among older respondents due to higher levels of disability and pain and-albeit to a lesser extent-lower levels of community involvement. Age-group differences in the models' intercepts and associations between individual characteristics and life circumstances-the so-called unexplained part of the decomposition models - again compensate for the expected disadvantage of older persons as measured by the emotion score. Yet, looking at the detailed decomposition results, we do not see any consistent pattern across countries in age-group differences in the relationship between specific individual characteristics and life circumstances on the one hand and the emotion score on the other, which might have suggested systematic differences in resilience to different life challenges across the two age groups.

Table 5 concludes our decomposition analyses for emotional well-being, using experienced utility as our outcome of interest. First, the estimated gender-adjusted mean age-group differences in experienced utility are negative for all study sites, i.e., indicating an overall advantage in terms of experienced utility in the older age group. Yet, the estimated age-group differences are generally small in magnitude and not statistically significantly different from zero. However, as is the case for the three other measures of subjective well-being, the explained parts of the Oaxaca-Blinder decompositionsbased on differences in individual characteristics and life circumstances-predict a disadvantage of older persons compared to their middle-aged counterparts (although the corresponding predictions for South Africa and Russia are not statistically different from zero). The predicted disadvantage of older persons mainly stems from their higher levels of disability and - to a lesser extent-higher levels of self-assessed pain. In addition, the fact that older individuals belong less frequently to the highest quartile of the income distribution seems to also contribute to decreasing their experienced utility. At the same time, the lower rate of employment among older adults yields a predicted advantage of older persons. In all countries, the explained part of the difference in experienced utility is overcompensated by an unexplained advantage of older persons, which stems from age-group differences in the models' intercepts and associations between experienced utility, and individual characteristics and life-circumstances. Disaggregation into specific variables does not, however, show consistent patterns across study sites, which would allow formulation of specific hypotheses regarding likely differences in resilience to specific life challenges across the two age groups. 
Table 4 Decomposition analysis of emotion score by country

\begin{tabular}{|c|c|c|c|c|c|c|}
\hline & Pooled & Ghana & India & China & South Africa & Russia \\
\hline $50-64$ & 0.02 & $0.06^{*}$ & 0.02 & -0.00 & -0.05 & 0.08 \\
\hline$\geq 65$ & $-0.04 *$ & $-0.08^{*}$ & -0.04 & 0.00 & $0.10^{*}$ & -0.11 \\
\hline Difference & $0.06 *$ & $0.14 * * *$ & 0.06 & -0.00 & -0.14 & $0.19^{*}$ \\
\hline Explained & $0.21 * * *$ & $0.21 * * *$ & $0.18 * * *$ & $0.14 * * *$ & $0.12 * * *$ & $0.31 * * *$ \\
\hline Unexplained & $-0.15 * * *$ & $-0.07 *$ & $-0.12 * * *$ & $-0.14 * * *$ & $-0.27 * * *$ & $-0.12 * *$ \\
\hline \multicolumn{7}{|c|}{ Panel A. Explained differences } \\
\hline Female & $0.01 * *$ & 0.00 & 0.00 & 0.00 & 0.00 & 0.02 \\
\hline Rural & -0.00 & 0.00 & -0.00 & $-0.02 * * *$ & 0.01 & 0.00 \\
\hline Married & -0.01 & 0.01 & $-0.03^{*}$ & 0.01 & 0.01 & -0.00 \\
\hline $\mathrm{Nb}$ of adults in household & 0.00 & -0.00 & -0.00 & -0.00 & 0.00 & 0.01 \\
\hline $\mathrm{Nb}$ of children in household & 0.00 & 0.00 & -0.00 & -0.00 & 0.00 & -0.02 \\
\hline Education years & -0.00 & -0.02 & -0.00 & $-0.01 *$ & -0.00 & -0.04 \\
\hline Working & $-0.04 * * *$ & $0.09 * * *$ & $-0.05 * * *$ & $-0.03 * *$ & -0.03 & -0.02 \\
\hline Q2: Permanent Income & -0.00 & -0.00 & 0.00 & -0.00 & 0.00 & -0.00 \\
\hline Q3: Permanent Income & $0.01 *$ & 0.00 & 0.00 & $0.01 * * *$ & 0.00 & -0.00 \\
\hline Q4: Permanent Income & $0.02 * * *$ & $0.02 * *$ & 0.00 & $0.02 * * *$ & -0.01 & 0.03 \\
\hline Victim & -0.00 & 0.00 & -0.00 & -0.00 & 0.00 & -0.00 \\
\hline WHO disability index & $0.14 * * *$ & -0.00 & $0.18 * * *$ & $0.08 * * *$ & 0.03 & $0.21 * * *$ \\
\hline Self-assessed pain & $0.07 * * *$ & $0.07 * * *$ & $0.08 * * *$ & $0.05 * * *$ & $0.07 * *$ & $0.10 * *$ \\
\hline Community involvement & $0.01 *$ & $0.04 * * *$ & 0.00 & $0.01 * * *$ & $0.05 * *$ & 0.00 \\
\hline Trust & $0.00 *$ & 0.01 & 0.00 & -0.00 & -0.00 & 0.01 \\
\hline Safety & $0.01 * * *$ & 0.00 & 0.00 & $0.01 * * *$ & -0.00 & 0.02 \\
\hline \multicolumn{7}{|c|}{ Panel B. Unexplained differences } \\
\hline Female & -0.01 & 0.01 & 0.02 & 0.00 & 0.05 & -0.04 \\
\hline Rural & 0.01 & -0.05 & 0.01 & -0.02 & -0.04 & -0.03 \\
\hline Married & 0.04 & 0.02 & 0.07 & $0.19 * *$ & 0.06 & -0.01 \\
\hline $\mathrm{Nb}$ of adults in household & -0.02 & -0.02 & 0.03 & $-0.11^{*}$ & -0.06 & -0.13 \\
\hline $\mathrm{Nb}$ of children in household & -0.02 & -0.03 & -0.05 & 0.02 & -0.02 & -0.02 \\
\hline Education years & -0.02 & -0.04 & -0.05 & 0.04 & -0.09 & -0.08 \\
\hline Working & 0.03 & -0.03 & 0.01 & $0.04 *$ & $0.11 * *$ & 0.02 \\
\hline Q2: Permanent Income & -0.00 & 0.05 & -0.01 & -0.02 & -0.03 & 0.01 \\
\hline Q3: Permanent Income & 0.01 & 0.04 & 0.01 & 0.01 & -0.03 & -0.01 \\
\hline Q4: Permanent Income & -0.01 & 0.00 & -0.01 & -0.02 & 0.00 & 0.02 \\
\hline Victim & 0.00 & 0.01 & 0.01 & -0.00 & 0.00 & -0.00 \\
\hline WHO disability index & $0.01 * *$ & 0.01 & -0.01 & $0.01 * * *$ & 0.00 & 0.03 \\
\hline Self-assessed pain & 0.00 & -0.00 & 0.01 & -0.00 & 0.00 & 0.01 \\
\hline Community involvement & 0.00 & 0.00 & -0.00 & 0.00 & -0.00 & 0.02 \\
\hline Trust & 0.00 & -0.00 & 0.00 & 0.00 & 0.00 & 0.00 \\
\hline Safety & -0.00 & 0.00 & -0.00 & -0.00 & 0.00 & -0.00 \\
\hline Constant & $-0.23 * *$ & -0.06 & -0.16 & $-0.29 *$ & -0.21 & 0.07 \\
\hline Observations & 21,478 & 3026 & 4832 & 8996 & 1999 & 2625 \\
\hline
\end{tabular}

The entries in each column are country-specific partial effects. Reported differences are measured in standard deviation units of each respective outcome of interest, whereby the standardization is performed at the country level. The pooled regression includes country fixed effects

$* p<0.10 ; * * p<0.05 ; * * * p<0.01$ 
Table 5 Decomposition analysis of experienced utility by country

\begin{tabular}{|c|c|c|c|c|c|c|}
\hline & Pooled & Ghana & India & China & South Africa & Russia \\
\hline $50-64$ & -0.02 & -0.02 & -0.01 & $-0.04 *$ & -0.05 & -0.01 \\
\hline$\geq 65$ & 0.04 & 0.03 & 0.03 & $0.06 * * *$ & 0.09 & 0.02 \\
\hline Difference & $-0.06^{*}$ & -0.05 & -0.04 & $-0.10 * * *$ & -0.14 & -0.03 \\
\hline Explained & $0.08 * * *$ & $0.07 * * *$ & $0.08 * *$ & $0.05 * *$ & 0.08 & 0.05 \\
\hline Unexplained & $-0.15 * * *$ & $-0.12 * * *$ & $-0.12 * *$ & $-0.14 * * *$ & $-0.21 * * *$ & -0.07 \\
\hline \multicolumn{7}{|c|}{ Panel A. Explained differences } \\
\hline Female & $0.00^{*}$ & 0.00 & 0.00 & 0.00 & 0.00 & 0.01 \\
\hline Rural & $-0.01 *$ & 0.00 & -0.00 & $-0.04 * * *$ & 0.00 & 0.00 \\
\hline Married & -0.02 & -0.01 & $-0.03 * *$ & 0.00 & 0.01 & -0.03 \\
\hline $\mathrm{Nb}$ of adults in household & -0.00 & -0.00 & -0.00 & $-0.01 * * *$ & 0.00 & 0.02 \\
\hline $\mathrm{Nb}$ of children in household & -0.00 & -0.00 & -0.01 & -0.00 & -0.00 & -0.00 \\
\hline Education years & 0.00 & -0.01 & 0.00 & -0.00 & 0.00 & -0.04 \\
\hline Working & $-0.06^{* * *}$ & 0.01 & $-0.04 * *$ & $-0.03 * *$ & -0.05 & $-0.17 * * *$ \\
\hline Q2: permanent income & $-0.00 *$ & -0.00 & 0.00 & $-0.01^{*}$ & 0.00 & -0.03 \\
\hline Q3: permanent income & $0.01 * *$ & 0.00 & -0.00 & $0.02 * * *$ & 0.00 & 0.01 \\
\hline Q4: permanent income & $0.02 * * *$ & $0.01 * *$ & 0.00 & $0.03 * * *$ & -0.01 & $0.08 *$ \\
\hline Victim & -0.00 & 0.00 & -0.00 & 0.00 & 0.00 & -0.00 \\
\hline WHO disability index & $0.10^{* * *}$ & $0.06^{* *}$ & $0.15^{* * *}$ & $0.03 * *$ & 0.08 & $0.18 * * *$ \\
\hline Self-assessed pain & $0.02 * * *$ & -0.01 & 0.02 & $0.02 * * *$ & $0.05 * *$ & 0.06 \\
\hline Community involvement & $-0.01 *$ & $0.03 * *$ & $-0.02 *$ & $0.01 * *$ & -0.00 & $-0.06^{*}$ \\
\hline Trust & 0.00 & -0.00 & -0.00 & -0.00 & -0.00 & -0.01 \\
\hline Safety & $0.01 * * *$ & 0.00 & 0.01 & $0.02 * * *$ & -0.00 & 0.03 \\
\hline \multicolumn{7}{|c|}{ Panel B. Unexplained differences } \\
\hline Female & 0.02 & 0.02 & -0.03 & 0.04 & $-0.25 *$ & 0.10 \\
\hline Rural & $0.07 *$ & -0.03 & 0.09 & $-0.07^{*}$ & 0.02 & $0.12 * *$ \\
\hline Married & -0.06 & -0.04 & -0.02 & 0.04 & -0.03 & -0.06 \\
\hline $\mathrm{Nb}$ of adults in household & -0.01 & -0.04 & 0.06 & -0.04 & -0.29 & -0.12 \\
\hline $\mathrm{Nb}$ of children in household & -0.01 & 0.02 & -0.04 & $0.04 * * *$ & -0.04 & -0.02 \\
\hline Education years & 0.03 & -0.03 & -0.06 & 0.03 & -0.09 & 0.11 \\
\hline Working & 0.03 & 0.03 & -0.01 & $0.06^{* *}$ & -0.01 & 0.05 \\
\hline Q2: permanent income & $-0.03^{*}$ & 0.02 & -0.05 & -0.02 & -0.05 & -0.04 \\
\hline Q3: permanent income & -0.00 & 0.01 & -0.01 & 0.02 & 0.00 & -0.05 \\
\hline Q4: permanent income & -0.02 & -0.00 & -0.01 & -0.03 & 0.06 & -0.03 \\
\hline Victim & -0.00 & 0.01 & -0.00 & 0.00 & -0.01 & -0.00 \\
\hline WHO disability index & $0.01 * *$ & 0.01 & -0.01 & $0.02 * * *$ & $0.05^{*}$ & 0.03 \\
\hline Self-assessed pain & -0.00 & -0.00 & 0.00 & -0.00 & -0.02 & 0.00 \\
\hline Community involvement & 0.00 & -0.00 & -0.01 & 0.00 & -0.02 & 0.02 \\
\hline Trust & 0.00 & 0.00 & 0.00 & 0.00 & 0.00 & 0.00 \\
\hline Safety & -0.00 & -0.00 & 0.00 & -0.00 & 0.00 & -0.00 \\
\hline Constant & -0.19 & -0.11 & -0.04 & $-0.23 *$ & 0.46 & -0.19 \\
\hline Observations & 21,478 & 3026 & 4832 & 8996 & 1999 & 2625 \\
\hline
\end{tabular}

The entries in each column are country-specific partial effects. Reported differences are measured in standard deviation units of each respective outcome of interest, whereby the standardization is performed at the country level. The pooled regression includes country fixed effects

$* p<0.10 ; * * p<0.05 ; * * * p<0.01$ 


\section{Discussion}

There are several conceptual and methodological challenges to a coherent interpretation of the current state of the evidence on the relationship between age and subjective well-being (Hansen and Slagsvold 2012). In particular, existing studies typically differ with respect to the concept of well-being under consideration (e.g. evaluative vs. emotional well-being), the setting (e.g. developed vs. developing countries), the study design (e.g. cross-sectional vs. longitudinal data), or model specifications, including whether or not to incorporate control variables into the statistical models and if so, which ones. Given the multiplicity of study designs and methodological differences across studies, it is often challenging to conclude on whether reported subjective well-being differences are generalizable or may be attributed to specific aspects of the data or empirical models.

In this context, our paper seeks to provide a unique and comprehensive assessment of the cross-sectional relationship between age and subjective well-being among older adults from five major low- and middle-income countries. Firstly, our analysis contrasts several measures of both evaluative and emotional well-being in the same study populations. Secondly, we analyze the relationship between age and subjective well-being with and without a broad set of controls for respondents' individual characteristics and life circumstances, which allows us to assess both gender-adjusted differences in well-being across age groups as well as the partial effects of age on well-being holding other factors fixed. In addition, we place the results from these two approaches within a unifying framework based on Oaxaca-Blinder decompositions, which provides us with detailed insights regarding the relationship between gender-adjusted and fully-adjusted differences in subjective well-being across age groups. Lastly, we perform our analysis in the context of the developing world, documenting the complex relationship between age and well-being for five low- and middle-income countries from different geographic regions and cultures. Since these countries differ vastly in many aspects, including in terms of institutional support for older persons, we would expect potentially different patterns in the relationship between age and subjective well-being across study countries, as well as compared to high-income countries, which have been the main focus of scientific inquiry on the relationship between age and well-being to date.

\subsection{Total Effects of Age on Subjective Well-Being}

With regard to the first research question-do older individuals have the same level of subjective well-being as middle-aged individuals?-results from the gender-adjusted regressions of age on our two measures of evaluative well-being show that older respondents generally report lower evaluative well-being than their middle-aged counterparts of the same gender, with the lowest average level of evaluative well-being in the oldest age group.

The gender-adjusted regression models of age on our two emotional well-being measures - the emotion score and experienced utility-show a different picture. Compared to evaluative well-being, our results suggest that emotional well-being is generally more stable across age groups (with small positive coefficients in the case of experienced utility) when only gender is controlled for.

\subsection{Partial Effects of Age on Subjective Well-Being}

Turning to our second research question-does the situation change when objective individual characteristics and life circumstances are taken into consideration?-we 
analyze the role of individual characteristics and life circumstances. Compared to our gender-adjusted results, our fully-adjusted regressions show that older individuals are generally not at a disadvantage as compared to their middle-aged counterparts. We find either no difference between age groups or a significant improvement of evaluative wellbeing across increasing age categories. This pattern suggests that it is not higher age per se which is responsible for the lower evaluative well-being observed in the genderadjusted models, but rather objective difficulties faced by older adults, notably challenges related to health and income.

Results from the multivariate regression models of age on the two emotional wellbeing measures-emotion score and experienced utility-are comparable to what we observe for evaluative well-being, i.e., older age groups report significantly higher levels of emotional well-being once individual characteristics and life circumstances are taken into consideration.

\subsection{Interpretation}

The fact that gender-adjusted results show decreasing evaluative and stable emotional well-being profiles in age stands in contrast to most findings from high-income countries, which suggest positive age gradients in both evaluative and emotional well-being at higher ages. This difference could be linked to specific challenges faced by older adults, which may be more widespread or severe in low- and middle-income settings. Among other factors, exclusion of informal workers from pension schemes, the absence of a social welfare system and increased age-dependent needs for health services in the context of weak health systems may all contribute to the lower levels of well-being of older adults in developing countries. Once we control for individuals' characteristics and life circumstances, our results get closer to what is generally described in the literature for high-income countries, namely higher levels of both evaluative and emotional well-being among older age groups. Our estimates of the fully-adjusted relationship between age and well-being isolate the partial effect of age on well-being-thus eliminating the potentially mediating role of certain channels such as bad health and poverty, which may be especially challenging in developing countries. The remaining positive partial association between age and subjective well-being could be due to a range of non-mutually exclusive factors associated with aging. We present a few examples below. First, the emotional maturity hypothesis posits that older adults show less severe reactions to stressful life events and recover faster from these stressors (Kato et al. 1996; Ticehurst et al. 1996). Second, the socio-emotional selectivity theory suggests changes in emotion regulation with age which predict higher positive and lower negative affect, resulting in improved emotional well-being (e.g. Carstensen 1995; Carstensen et al. 1999). Third, the selective optimization with compensation theory (Baltes and Baltes 1990) proposes that older adults use accumulated experience to optimize performance and compensate limitations. Fourth, personality may constitute a stabilizing factor: while adverse life events tend to temporarily diminish subjective well-being, the latter converges back to the level determined by personality traits (Diener et al. 2003). Finally, older persons may develop accommodative strategies, for example through the lowering of aspirations, needs and comparison benchmarks (George 2006). 


\subsection{Association with Individual Characteristics and Life Circumstances}

Exploring the association between the two dimensions of subjective well-being and individuals' life circumstances reveals largely expected patterns. Evaluative well-being - as measured by life satisfaction and the WHOQoL-8 score-tends to be higher for individuals who are working, who have higher economic status, lower levels of disability and pain and higher community involvement, trust in others and in their personal safety. However, we find no consistent pattern for the association of education level with evaluative wellbeing. In general, we identify fewer consistent associations of life circumstances with emotional well-being, though higher levels of economic status and lower levels of disability and pain appear to also be associated with higher levels of emotional well-being. Interestingly, working seems to be positively associated with evaluative but either not at all or negatively associated with emotional well-being. This result is consistent, for example, with findings by Knabe et al. (2010) for Germany, who show that despite reporting lower levels of life satisfaction, unemployed individuals have similar levels of experienced utility than employed individuals. This finding suggests that employment may be an important aspect of self-conceptualization, but at the same time is often considered as an unpleasant activity (White and Dolan 2009). More generally, evaluative and emotional well-being frequently show different associations with important aspects of life (Deaton and Stone 2013; Kahneman and Deaton 2010; Kapteyn et al. 2015; Stone et al. 2010), which represents another rationale for analyzing these two aspects of subjective well-being in parallel to get a more comprehensive picture of social progress and well-being in the population.

\subsection{Oaxaca-Blinder Decomposition Analysis}

Finally, we focus on Research Questions 3 and 4-to what extent do differences in objective life circumstances explain differences in subjective well-being between older and middleaged persons? and are older persons better or worse than their middle-aged counterparts at dealing with objective life circumstances and individual characteristics?, respectively. The Oaxaca-Blinder decompositions suggest that-based on age-group differences in life circumstances such as economic status, health, and community characteristics-older persons should suffer from larger disadvantages in terms of both evaluative and emotional well-being than actually observed. At the same time, age-group differences in the association between life circumstances and subjective well-being seem relatively heterogeneous and inconsistent across study sites. This suggests that compensating effects may be more related to older age as such than to higher levels of resilience or better coping mechanisms for certain specific adversities challenging older persons. The fact that - in multivariable models - the partial association of age per se with subjective well-being is positive in spite of the potentially adverse circumstances faced by older individuals (in particular in terms of health and income) may be understood through the lens of the compensatory mechanisms discussed above.

\subsection{Strength and Limitations}

This paper provides a comparison of gender- and fully-adjusted analyses of the relationship between age and subjective well-being by means of multiple measures for evaluative and emotional well-being using a large-scale multi-country dataset from five low- and middleincome countries. In particular, we exploit the fact that SAGE data contains information 
regarding several countries to check the robustness of our findings across different geographic regions, cultures and stages of economic development. However, there are several limitations to our analysis. First, we cannot interpret any of our estimated descriptive associations as causal effects of age(ing) on subjective well-being due to potential issues of confounding and selection in cross-sectional data. In particular, the cross-sectional nature of our data does not allow to take potential cohort effects into account. Our analysis thus does not reflect the way subjective well-being evolves as people age, but rather describes the existing differences between distinct age groups at a certain point in time. Secondly, our analyses rely on the cardinal interpretation of our well-being measures, which may be problematic in the case of life satisfaction. However, analyses based on parametric ordered probit models for this outcome measure resulted in largely similar findings. Thirdly, as with most analyses based on survey data, our results may suffer from selection bias. In our context, selective participation and attrition may be especially important due to generally lower participation rates of frail or institutionalized individuals in population-based aging surveys. Moreover, as happier individuals tend to live longer (Gana et al. 2016; Steptoe and Wardle 2012), our samples of older individuals may be "enriched" with people who had higher levels of subjective wellbeing throughout their entire life such as intrinsically more optimistic people. Finally, there may also be age-related reporting heterogeneity in subjective well-being measures. Indeed, some studies suggest that older persons may be less willing to report extreme emotions in a survey (Diener et al. 1985; Gibson 1997), even if existing evidence regarding the latter based on European data would rather suggest that our findings could understate the true size of the partial association of age with subjective well-being (Angelini et al. 2012). More research is thus needed to address these limitations and in order to allow inference of a causal relationship, in particular with the use of longitudinal data. Nevertheless, our study makes a valuable contribution to documenting age differences in subjective well-being among older adults from different developing country settings, proposing ways of reflection and interpretation of these differences and thereby helping to generate further hypotheses for future research.

\section{Conclusion}

Our paper investigates the relationship between age and different dimensions of subjective wellbeing as well as the potential roles of possible mediators, moderators and confounding variables, among older adults from five low- and middle-income countries.

We find that the relationship between age and subjective well-being differs depending on the dimension under consideration and on whether individual characteristics and life circumstances are taken into account. By performing both gender- and fullyadjusted analyses, we contribute to advancing the longstanding debate between supporters of unadjusted and adjusted approaches in well-being research (Blanchflower and Oswald 2008, 2009; Glenn 2009). Specifically, our results suggest that both types of analyses provide important and complementary viewpoints and should therefore be performed in parallel. When considering the "raw" differences (i.e., controlling only for gender) between age and subjective well-being, we see that older adults have lower evaluative but similar emotional well-being than their middle-aged counterparts. Including additional covariates blunts or even inverts the negative relationship between age and evaluative well-being, and results in consistent positive associations between age and emotional well-being. This implies that old age per se may influence subjective well-being positively, and that decreases in evaluative well-being between age categories might be linked to objective challenges faced by older adults. These findings 
resonate with a range of theories from the psychology of aging, such as the emotional maturity hypothesis (Kato et al. 1996; Ticehurst et al. 1996), the socio-emotional selectivity (e.g. Carstensen 1995; Carstensen et al. 1999), or the selective optimization with compensation theory (Baltes and Baltes 1990). Our Oaxaca decompositions confirm these results and suggest that lower income and poorer health (as well as community involvement to a lesser extent) are the main drivers of the age gap in subjective well-being. In view of the global aging phenomenon and of the need to maximize subjective well-being in an increasing portion of the population, these results hint to the importance of limiting or compensating age-related disability and preserving income through appropriate health and social policies. Such policies could help reduce unadjusted gaps in subjective well-being between older adults and their middle-aged counterparts, thereby helping to address existing age-related disparities in subjective wellbeing in the context of countries with less developed welfare states.

Authors' Contribution GF contributed to this work during her employment at the University of Lausanne, Faculty of Business and Economics. She has since then become an employee of the World Health Organization (Health Financing Department), 20 avenue Appia CH-1211 Geneva 27, Switzerland. The arguments made in this paper are entirely those of the authors. They do not necessarily represent the views of the World Health Organization. MI contributed to this work during his PhD studies at the University of Lausanne, Faculty of Business and Economics. He has since then become an employee of ViiV Healthcare (Head of Market Access and Healthcare Solutions), Prinzregentenpl. 9, 81675 Munich, Germany. JM is a professor of Economics at the University of Lausanne, Faculty of Business and Economics, Internef, Dorigny, 1015 Lausanne, Switzerland.

Funding Open access funding provided by University of Lausanne Jürgen Maurer acknowledges support for this research by the Swiss Agency for Development and Cooperation (SDC) and the Swiss National Science Foundation through the Swiss Programme for Research on Global Issues for Development (r4d programme) by the grant "Inclusive social protection for chronic health problems" (Grant Number: 400640_160374).

Availability of Data and Materials The datasets analyzed during the current study are available from the World Health Organization's website.

\section{Compliance with Ethical Standards}

Conflict of interest The authors declare that there is no conflict of interest.

Open Access This article is licensed under a Creative Commons Attribution 4.0 International License, which permits use, sharing, adaptation, distribution and reproduction in any medium or format, as long as you give appropriate credit to the original author(s) and the source, provide a link to the Creative Commons licence, and indicate if changes were made. The images or other third party material in this article are included in the article's Creative Commons licence, unless indicated otherwise in a credit line to the material. If material is not included in the article's Creative Commons licence and your intended use is not permitted by statutory regulation or exceeds the permitted use, you will need to obtain permission directly from the copyright holder. To view a copy of this licence, visit http://creativecommons.org/licenses/by/4.0/. 


\section{Appendix 1}

See Table 6.

Table 6 Partial association between age and life satisfaction

\begin{tabular}{|c|c|c|c|c|c|c|}
\hline & Pooled & Ghana & India & China & South Africa & Russia \\
\hline \multicolumn{7}{|l|}{ Panel A. Gender-adjusted } \\
\hline $60-69$ & $-0.09 * * *$ & $-0.14 * * *$ & $-0.14 * * *$ & -0.01 & 0.03 & -0.13 \\
\hline $70-79$ & $-0.19 * * *$ & $-0.27 * * *$ & $-0.22 * * *$ & $-0.08 *$ & 0.10 & $-0.38 * * *$ \\
\hline $80+$ & $-0.39 * * *$ & $-0.67 * * *$ & $-0.54 * * *$ & $-0.23 * * *$ & -0.11 & $-0.42 * * *$ \\
\hline Female & $-0.12 * * *$ & $-0.16^{* * *}$ & $-0.16^{* * *}$ & $-0.07 * * *$ & -0.10 & $-0.13^{*}$ \\
\hline Constant & $0.14 * * *$ & $0.24 * * *$ & $0.18 * * *$ & $0.07 * *$ & 0.04 & $0.22 * * *$ \\
\hline Country & Yes & No & No & No & No & No \\
\hline \multicolumn{7}{|l|}{ Panel B. Fully-adjusted } \\
\hline $60-69$ & $0.08 * * *$ & $0.08 *$ & 0.02 & $0.14 * * *$ & $0.19 * * *$ & 0.07 \\
\hline $70-79$ & $0.19 * * *$ & $0.18 * * *$ & $0.09 * *$ & $0.30 * * *$ & $0.35 * * *$ & 0.11 \\
\hline $80+$ & $0.27 * * *$ & 0.08 & 0.04 & $0.42 * * *$ & $0.35 * *$ & $0.35 * * *$ \\
\hline Female & $0.08 * * *$ & $0.14 * * *$ & $0.16^{* * *}$ & $0.06 * *$ & $0.11 *$ & 0.00 \\
\hline Rural & 0.06 & -0.05 & 0.09 & -0.01 & -0.07 & 0.06 \\
\hline Married & 0.01 & $0.16^{* * *}$ & -0.01 & $0.08 * *$ & $0.19 * * *$ & -0.06 \\
\hline Number of adults in household & -0.00 & -0.01 & 0.01 & -0.03 & 0.02 & -0.04 \\
\hline $\begin{array}{l}\text { Number of children in house- } \\
\text { hold }\end{array}$ & -0.00 & -0.01 & 0.00 & -0.02 & -0.01 & -0.08 \\
\hline Education (nb of years) & -0.00 & 0.00 & 0.01 & -0.00 & -0.01 & -0.02 \\
\hline Working & 0.03 & $0.09 *$ & 0.01 & $0.13 * * *$ & 0.12 & -0.11 \\
\hline Q2: Permanent Income & $0.17 * * *$ & $0.11 *$ & 0.06 & $0.30 * * *$ & $0.31 * * *$ & 0.13 \\
\hline Q3: Permanent Income & $0.24 * * *$ & $0.18 * * *$ & $0.12 * *$ & $0.42 * * *$ & $0.50 * * *$ & 0.04 \\
\hline Q4: Permanent Income & $0.40 * * *$ & $0.43 * * *$ & $0.31 * * *$ & $0.50 * * *$ & $0.62 * * *$ & $0.36 * * *$ \\
\hline WHO disability index & $-0.31 * * *$ & $-0.41 * * *$ & $-0.38 * * *$ & $-0.24 * * *$ & $-0.38 * * *$ & $-0.35 * * *$ \\
\hline Self-assessed pain & $-0.13 * * *$ & $-0.10^{* * *}$ & $-0.08 * * *$ & $-0.16^{* * *}$ & $-0.09 * *$ & $-0.14 * *$ \\
\hline Community Involvement & $0.07 * * *$ & 0.04 & $0.09 * * *$ & $0.05 * * *$ & -0.04 & $0.12 * * *$ \\
\hline Trust & $0.08 * * *$ & $0.06 * * *$ & $0.05 * *$ & $0.09 * * *$ & -0.00 & $0.09 *$ \\
\hline Safety & $0.09 * * *$ & 0.03 & $0.03 *$ & $0.11 * * *$ & $0.10 * * *$ & $0.16^{* * * *}$ \\
\hline Victim & -0.01 & -0.16 & 0.03 & -0.07 & $0.19 *$ & -0.15 \\
\hline Constant & $-0.37 * * *$ & $-0.39 * * *$ & $-0.37 * * *$ & $-0.53 * * *$ & $-0.65^{* * *}$ & 0.12 \\
\hline Country & Yes & No & No & No & No & No \\
\hline Observations & 21,478 & 3026 & 4832 & 8996 & 1999 & 2625 \\
\hline
\end{tabular}

The entries in each column are country-specific partial effects. Reported differences are measured in standard deviation units of each respective outcome of interest, whereby the standardization is performed at the country level. The pooled regression includes country fixed effects

$* p<0.10 ; * * p<0.05 ; * * * p<0.01$ 


\section{Appendix 2}

See Table 7.

Table 7 Partial association between age and WHOQOL-8 Score

\begin{tabular}{|c|c|c|c|c|c|c|}
\hline & Pooled & Ghana & India & China & South Africa & Russia \\
\hline \multicolumn{7}{|l|}{ Panel A. Gender-adjusted } \\
\hline $60-69$ & $-0.18 * * *$ & $-0.26^{* * *}$ & $-0.24 * * *$ & $-0.08 * * *$ & 0.03 & $-0.26^{* * *}$ \\
\hline $70-79$ & $-0.38 * * *$ & $-0.50 * * *$ & $-0.41 * * *$ & $-0.22 * * *$ & -0.03 & $-0.66^{* * *}$ \\
\hline $80+$ & $-0.58 * * *$ & $-0.94 * * *$ & $-0.71 * * *$ & $-0.46^{* * *}$ & $-0.26^{*}$ & $-0.61 * * *$ \\
\hline Female & $-0.21 * * *$ & $-0.27 * * *$ & $-0.28 * * *$ & $-0.11 * * *$ & $-0.17 * *$ & $-0.26 * * *$ \\
\hline Constant & $0.26 * * *$ & $0.40 * * *$ & $0.31 * * *$ & $0.14 * * *$ & 0.11 & $0.41 * * *$ \\
\hline Country & Yes & No & No & No & No & No \\
\hline \multicolumn{7}{|l|}{ Panel B. Fully-adjusted } \\
\hline $60-69$ & $0.06 * * *$ & 0.01 & -0.01 & $0.11 * * *$ & $0.23 * * *$ & 0.08 \\
\hline $70-79$ & $0.15^{* * *}$ & 0.06 & 0.02 & $0.25 * * *$ & $0.28 * * *$ & 0.14 \\
\hline $80+$ & $0.32 * * *$ & -0.03 & 0.09 & $0.37 * * *$ & $0.34 * *$ & $0.55^{* * *}$ \\
\hline Female & $0.07 * * *$ & 0.03 & $0.19 * * *$ & $0.05 * *$ & 0.09 & -0.06 \\
\hline Rural & 0.01 & -0.08 & 0.02 & -0.08 & -0.10 & 0.12 \\
\hline Married & $0.07 * * *$ & 0.05 & 0.07 & $0.08 * *$ & $0.21 * * *$ & 0.10 \\
\hline Number of adults in household & -0.01 & -0.01 & 0.01 & $-0.03 * *$ & -0.01 & $-0.08 * * *$ \\
\hline $\begin{array}{l}\text { Number of children in house- } \\
\text { hold }\end{array}$ & $0.01 *$ & $-0.02 * *$ & $0.02 * *$ & 0.01 & -0.02 & -0.05 \\
\hline Education (nb of years) & $0.01 * * *$ & $0.01 *$ & $0.01 * * *$ & 0.00 & 0.00 & 0.00 \\
\hline Working & $0.10 * * *$ & $0.18 * * *$ & $0.09 * * *$ & $0.17 * * *$ & $0.19 * *$ & 0.10 \\
\hline Q2: Permanent Income & $0.21 * * *$ & $0.19 * * *$ & $0.12 * *$ & $0.28 * * *$ & $0.36 * * *$ & $0.20 * *$ \\
\hline Q3: Permanent Income & $0.31 * * *$ & $0.21 * * *$ & $0.29 * * *$ & $0.42 * * *$ & $0.48 * * *$ & 0.06 \\
\hline Q4: Permanent Income & $0.51 * * *$ & $0.55^{* * *}$ & $0.51 * * *$ & $0.56^{* * *}$ & $0.79 * * *$ & $0.34 * * *$ \\
\hline WHO disability index & $-0.39 * * *$ & $-0.46^{* * *}$ & $-0.45 * * *$ & $-0.32 * * *$ & $-0.36 * * *$ & $-0.43 * * *$ \\
\hline Self-assessed pain & $-0.18 * * *$ & $-0.13^{* * *}$ & $-0.12 * * *$ & $-0.21 * * *$ & $-0.17 * * *$ & $-0.21 * * *$ \\
\hline Community Involvement & $0.07 * * *$ & $0.08 * * *$ & $0.11 * * *$ & $0.05 * * *$ & 0.04 & $0.09 * *$ \\
\hline Trust & $0.10^{* * *}$ & $0.07 * * *$ & $0.09 * * *$ & $0.11 * * *$ & -0.01 & $0.11^{* *}$ \\
\hline Safety & $0.10 * * *$ & $0.04 * *$ & $0.07 * * *$ & $0.11 * * *$ & $0.10 * * *$ & $0.15^{* * *} *$ \\
\hline Victim & -0.09 & $-0.17 * *$ & -0.08 & -0.09 & 0.07 & $-0.21^{*}$ \\
\hline Constant & $-0.51 * * *$ & $-0.34 * * *$ & $-0.55^{* * *}$ & $-0.50 * * *$ & $-0.67 * * *$ & -0.17 \\
\hline Country & Yes & No & No & No & No & No \\
\hline Observations & 21,478 & 3026 & 4832 & 8996 & 1999 & 2625 \\
\hline
\end{tabular}

The entries in each column are country-specific partial effects. Reported differences are measured in standard deviation units of each respective outcome of interest, whereby the standardization is performed at the country level. The pooled regression includes country fixed effects

$* p<0.10$; ** $p<0.05 ; * * * p<0.01$ 


\section{Appendix 3}

See Table 8.

Table 8 Partial association between age and emotion score

\begin{tabular}{|c|c|c|c|c|c|c|}
\hline & Pooled & Ghana & India & China & South Africa & Russia \\
\hline \multicolumn{7}{|l|}{ Panel A. Gender-adjusted } \\
\hline $60-69$ & 0.01 & $-0.10^{* *}$ & 0.01 & 0.03 & $0.19 * *$ & -0.03 \\
\hline $70-79$ & -0.01 & $-0.12 * *$ & -0.02 & 0.06 & $0.19^{*}$ & $-0.17^{*}$ \\
\hline $80+$ & $-0.11 * *$ & $-0.27 * * *$ & -0.05 & -0.10 & $0.38 * * *$ & $-0.22 * *$ \\
\hline Female & $-0.21 * * *$ & $-0.16^{* * *}$ & $-0.31 * * *$ & $-0.10 * * *$ & $-0.19 * * *$ & $-0.25 * * *$ \\
\hline Constant & $0.11 * * *$ & $0.15 * * *$ & $0.15 * * *$ & 0.04 & 0.01 & $0.21 * *$ \\
\hline Country & Yes & No & No & No & No & No \\
\hline \multicolumn{7}{|l|}{ Panel B. Fully-adjusted } \\
\hline $60-69$ & $0.14 * * *$ & 0.04 & $0.13 * * *$ & $0.12 * * *$ & $0.29 * * *$ & $0.20 * *$ \\
\hline $70-79$ & $0.28 * * *$ & $0.16^{* * *}$ & $0.20 * * *$ & $0.30 * * *$ & $0.37 * * *$ & $0.30 * * *$ \\
\hline $80+$ & $0.41 * * *$ & $0.14^{*}$ & $0.40 * * *$ & $0.35 * * *$ & $0.71 * * *$ & $0.46^{* * *}$ \\
\hline Female & $-0.07 * * *$ & -0.02 & $-0.15 * * *$ & -0.01 & -0.05 & $-0.11 *$ \\
\hline Rural & -0.04 & -0.03 & -0.05 & $-0.14 * * *$ & $-0.16^{*}$ & 0.11 \\
\hline Married & 0.03 & 0.07 & -0.04 & $0.12 * * *$ & $0.14^{*}$ & 0.02 \\
\hline Number of adults in household & 0.01 & -0.02 & 0.01 & -0.01 & -0.03 & 0.03 \\
\hline $\begin{array}{l}\text { Number of children in house- } \\
\text { hold }\end{array}$ & -0.00 & 0.01 & 0.00 & 0.00 & -0.01 & $-0.22 * * *$ \\
\hline Education (nb of years) & 0.00 & -0.00 & -0.00 & -0.00 & 0.00 & -0.01 \\
\hline Working & $-0.05^{*}$ & $0.33 * * *$ & $-0.14 * * *$ & -0.02 & 0.01 & 0.08 \\
\hline Q2: Permanent Income & 0.06 & $0.10^{*}$ & 0.04 & 0.07 & 0.09 & 0.01 \\
\hline Q3: Permanent Income & $0.14 * * *$ & $0.23 * * *$ & $0.16 * * *$ & $0.19 * * *$ & 0.06 & -0.04 \\
\hline Q4: Permanent Income & $0.26^{* * *}$ & $0.29 * * *$ & $0.30 * * *$ & $0.24 * * *$ & 0.16 & 0.14 \\
\hline WHO disability index & $-0.24 * * *$ & -0.01 & $-0.33 * * *$ & $-0.17 * * *$ & $-0.11 *$ & $-0.27 * * *$ \\
\hline Self-assessed pain & $-0.18 * * *$ & $-0.17 * * *$ & $-0.19 * * *$ & $-0.19 * * *$ & $-0.16^{* * *}$ & $-0.14 * * *$ \\
\hline Community Involvement & $0.03 * * *$ & $0.12 * * *$ & 0.02 & $0.05 * * *$ & $0.13 * * *$ & 0.01 \\
\hline Trust & $0.03 * *$ & $-0.11 * * *$ & 0.01 & $0.03 * *$ & -0.04 & 0.05 \\
\hline Safety & $0.06 * * *$ & $0.11 * * *$ & 0.01 & $0.09 * * *$ & -0.00 & $0.07 *$ \\
\hline Victim & $-0.21 * * *$ & 0.11 & $-0.28 * * *$ & -0.16 & 0.03 & -0.17 \\
\hline Constant & $-0.20 * * *$ & $-0.42 * * *$ & -0.06 & $-0.23 * * *$ & -0.15 & -0.12 \\
\hline Country & Yes & No & No & No & No & No \\
\hline Observations & 21,478 & 3026 & 4832 & 8996 & 1999 & 2625 \\
\hline
\end{tabular}

The entries in each column are country-specific partial effects. Reported differences are measured in standard deviation units of each respective outcome of interest, whereby the standardization is performed at the country level. The pooled regression includes country fixed effects

$* p<0.10 ; * * p<0.05 ; * * * p<0.01$ 


\section{Appendix 4}

See Table 9.

Table 9 Partial association between age and experienced utility

\begin{tabular}{|c|c|c|c|c|c|c|}
\hline & Pooled & Ghana & India & China & South Africa & Russia \\
\hline \multicolumn{7}{|l|}{ Panel A. Gender-adjusted } \\
\hline $60-69$ & $0.06^{* *}$ & $0.12 * *$ & 0.07 & $0.06^{* *}$ & $0.28^{* * * *}$ & -0.01 \\
\hline 70-79 & $0.12 * * *$ & $0.09 *$ & $0.13^{*}$ & $0.14 * * *$ & 0.14 & 0.08 \\
\hline $80+$ & 0.03 & 0.06 & -0.10 & $0.13^{* *}$ & $0.25 * *$ & 0.05 \\
\hline Female & $-0.13 * * *$ & $-0.10^{* *}$ & $-0.15 * * *$ & $-0.06^{* * *}$ & $-0.14 * *$ & $-0.20 * *$ \\
\hline Constant & 0.02 & -0.01 & 0.04 & -0.02 & -0.03 & 0.10 \\
\hline Country & Yes & No & No & No & No & No \\
\hline \multicolumn{7}{|l|}{ Panel B. Fully-adjusted } \\
\hline $60-69$ & $0.12 * * *$ & $0.18^{* * *}$ & $0.12^{* * *}$ & $0.11 * * *$ & $0.36^{* * *}$ & -0.00 \\
\hline $70-79$ & $0.27 * * *$ & $0.22 * * *$ & $0.25^{* * *}$ & $0.27 * * *$ & $0.25^{*}$ & 0.19 \\
\hline $80+$ & $0.32 * * *$ & $0.26^{* *}$ & 0.14 & $0.40 * * *$ & $0.49^{* * * *}$ & $0.28^{*}$ \\
\hline Female & $-0.05^{*}$ & -0.05 & -0.08 & 0.00 & -0.03 & -0.10 \\
\hline Rural & $-0.09 *$ & -0.06 & -0.06 & $-0.28 * * *$ & -0.06 & 0.07 \\
\hline Married & -0.01 & -0.00 & $-0.08^{*}$ & $0.09 *$ & $0.17 * *$ & -0.11 \\
\hline Number of adults in household & -0.01 & $-0.04 * * *$ & 0.01 & $-0.04 * *$ & $-0.09 *$ & 0.03 \\
\hline $\begin{array}{l}\text { Number of children in house- } \\
\text { hold }\end{array}$ & 0.01 & 0.00 & 0.01 & 0.00 & 0.04 & -0.03 \\
\hline Education (nb of years) & 0.00 & 0.00 & 0.01 & 0.00 & 0.01 & -0.01 \\
\hline Working & $-0.10 * * *$ & 0.08 & $-0.09 * *$ & -0.03 & -0.05 & $-0.25 * *$ \\
\hline Q2: Permanent Income & $0.12 * * *$ & 0.07 & 0.07 & $0.13 * * *$ & 0.07 & $0.21 *$ \\
\hline Q3: Permanent Income & $0.18^{* * *}$ & $0.18 * * *$ & -0.01 & $0.30 * * *$ & $0.18^{*}$ & 0.20 \\
\hline Q4: Permanent Income & $0.30^{* * * *}$ & $0.21 * * *$ & $0.21 * * *$ & $0.31 * * *$ & 0.16 & $0.38^{* * *}$ \\
\hline WHO disability index & $-0.18 * * *$ & $-0.10^{* * *}$ & $-0.26 * * *$ & $-0.08^{* * *}$ & $-0.17 * * *$ & $-0.23 * * *$ \\
\hline Self-assessed pain & $-0.06 * * *$ & 0.03 & $-0.05^{*}$ & $-0.06 * * *$ & $-0.11 * *$ & $-0.07 *$ \\
\hline Community Involvement & -0.02 & $0.08 * * *$ & $-0.05^{*}$ & 0.03 & -0.00 & $-0.09 * *$ \\
\hline Trust & 0.00 & 0.01 & 0.00 & 0.02 & -0.04 & -0.03 \\
\hline Safety & $0.12^{* * *}$ & $0.04 *$ & $0.10^{* * *}$ & $0.15 * * *$ & -0.02 & $0.13 * * *$ \\
\hline Victim & -0.03 & 0.05 & -0.08 & 0.02 & 0.07 & -0.01 \\
\hline Constant & $-0.14 * *$ & -0.11 & -0.06 & -0.14 & -0.10 & -0.05 \\
\hline Country & Yes & No & No & No & No & No \\
\hline Observations & 21,478 & 3026 & 4832 & 8996 & 1999 & 2625 \\
\hline
\end{tabular}

The entries in each column are country-specific partial effects. Reported differences are measured in standard deviation units of each respective outcome of interest, whereby the standardization is performed at the country level. The pooled regression includes country fixed effects

$* p<0.10 ; * * p<0.05 ; * * * p<0.01$ 


\section{References}

Angelini, V., Cavapozzi, D., Corazzini, L., \& Paccagnella, O. (2012). Age, health and life satisfaction among older Europeans. Social Indicators Research, 105(2), 293-308. https://doi.org/10.1007/s1120 5-011-9882-X.

Baltes, P. B., \& Baltes, M. M. (1990). Psychological perspectives on successful aging: The model of selective optimization with compensation. In P. B. Baltes \& M. M. Baltes (Eds.), successful aging (pp. 1-34). Cambridge: Cambridge University Press. https://doi.org/10.1017/CBO9780511665684.003.

Blanchflower, D. G., \& Oswald, A. J. (2008). Is well-being U-shaped over the life cycle? Social Science and Medicine, 66(8), 1733-1749. https://doi.org/10.1016/j.socscimed.2008.01.030.

Blanchflower, D. G., \& Oswald, A. J. (2009). The U-shape without controls: A response to Glenn. Social Science and Medicine, 69(4), 486-488. https://doi.org/10.1016/j.socscimed.2009.05.022.

Bond, T. N., \& Lang, K. (2019). The Sad Truth about Happiness Scales. Journal of Political Economy, 127(4), 1629-1640. https://doi.org/10.1086/701679.

Carstensen, L. L. (1995). Evidence for a life-span theory of socioemotional selectivity. Current Directions in Psychological Science, 4(5), 151-156.

Carstensen, L. L., Isaacowitz, D. M., \& Charles, S. T. (1999). Taking time seriously: A theory of socioemotional selectivity. American Psychologist, 54(3), 165-181. https://doi. org/10.1037//0003-066X.54.3.165.

Carstensen, L. L., Pasupathi, M., Mayr, U., \& Nesselroade, J. R. (2000). Emotional experience in everyday life across the adult life span. Journal of Personality and Social Psychology, 79(4), 644. https://doi. org/10.1037/0022-3514.79.4.644.

Carstensen, L. L., Turan, B., Scheibe, S., Ram, N., Ersner-Hershfield, H., Samanez-Larkin, G. R., et al. (2011). Emotional experience improves with age: Evidence based on over 10 years of experience sampling. Psychology and Aging, 26(1), 21-33. https://doi.org/10.1037/a0021285.

Chen, C. (2001). Aging and life satisfaction. Social Indicators Research, 54(1), 57-79. https://doi. org/10.1023/A:1007260728792.

Chen, F., \& Short, S. E. (2008). Household context and subjective well-being among the oldest old in China. Journal of Family Issues, 29(10), 1379-1403. https://doi.org/10.1177/0192513X07313602.

Deaton, A. (2008). Income, health and wellbeing around the world: Evidence from the Gallup World Poll. The Journal of Economic Perspectives : A Journal of the American Economic Association, 22(2), 53-72. https://doi.org/10.1257/jep.22.2.53.

Deaton, A. Z. S., \& Stone, A. A. (2013). Economic analysis of subjective well-being two happiness puzzles.

Diener, E., Oishi, S., \& Lucas, R. E. (2003). Personality, culture, and subjective well-being: Emotional and cognitive evaluations of life. Annual Review of Psychology, 54(1), 403-425. https://doi.org/10.1146/ annurev.psych.54.101601.145056.

Diener, E., Sandvik, E., \& Larsen, R. J. (1985). Age and sex effects for emotional intensity. Developmental Psychology, 21(3), 542-546. https://doi.org/10.1037/0012-1649.21.3.542.

Dolan, P., Kudrna, L., \& Stone, A. (2017). The measure matters: An investigation of evaluative and experience-based measures of wellbeing in time use data. Social Indicators Research, 134(1), 57-73. https:// doi.org/10.1007/s11205-016-1429-8.

Dolan, P., Layard, R., \& Metcalfe, R. (2011). Measuring subjective wellbeing for public policy: Recommendations on Measures (No. 23).

Ferrer-i-Carbonell, A., \& Frijters, P. (2004). How important is methodology for the estimates of the determinants of happiness? The Economic Journal, 114(497), 641-659. https://doi.org/10.111 1/j.1468-0297.2004.00235.x.

Flores, G., Ingenhaag, M., \& Maurer, J. (2015). An anatomy of old-age disability: Time use, affect and experienced utility. Journal of Health Economics, 44, 150-160. https://doi.org/10.1016/j.jheal eco.2015.09.003.

Flores, G., Kieny, C., \& Maurer, J. (2020). Deconstructing gender differences in experienced well-being among older adults in the developing World: The roles of time use and activity-specific affective experiences. Social Indicators Research. https://doi.org/10.1007/s11205-020-02435-3.

Fortin, N., Helliwell, J. F., \& Wang, S. (2015). How does subjective well-being vary around the 42 world by gender and age? (J. F. Helliwell, R. Layard, and J. Sachs). Sustainable development solutions network. http://worldhappiness.report/wp-content/uploads/sites/2/2015/04/WHR15.pdf.

Frijters, P., \& Beatton, T. (2012). The mystery of the U-shaped relationship between happiness and age. Journal of Economic Behavior \& Organization, 82(2), 525-542. https://doi.org/10.1016/j. jebo.2012.03.008. 
Gana, K., Broc, G., Saada, Y., Amieva, H., \& Quintard, B. (2016). Subjective wellbeing and longevity: Findings from a 22-year cohort study. Journal of Psychosomatic Research, 85, 28-34. https://doi. org/10.1016/j.jpsychores.2016.04.004.

George, L. K. (2006). Perceived quality of life. In Handbook of aging and the social sciences (pp. 320-336). Elsevier. https://doi.org/10.1016/B978-012088388-2/50021-3.

Gibson, S. J. (1997). The measurement of mood states in older adults. The Journals of Gerontology Series B: Psychological Sciences and Social Sciences, 52B(4), P167-P174. https://doi.org/10.1093/geron b/52B.4.P167.

Glenn, N. (2009). Is the apparent U-shape of well-being over the life course a result of inappropriate use of control variables? A commentary on Blanchflower and Oswald (66: 8, 2008, 1733-1749). Social Science and Medicine, 69(4), 481-485. https://doi.org/10.1016/j.socscimed.2009.05.038.

Graham, C., \& Ruiz Pozuelo, J. (2017). Happiness, stress, and age: How the U curve varies across people and places. Journal of Population Economics, 30(1), 225-264. https://doi.org/10.1007/s0014 8-016-0611-2.

Gwozdz, W., \& Sousa-Poza, A. (2010). Ageing, health and life satisfaction of the oldest old: An analysis for Germany. Social Indicators Research, 97(3), 397-417. https://doi.org/10.1007/s11205-009-9508-8.

Hansen, T., \& Slagsvold, B. (2012). The age and subjective well-being paradox revisited: A multidimensional perspective. Norsk Epidemiologi, 22(2). https://doi.org/10.5324/nje.v22i2.1565.

Helliwell, J. F., \& Wang, S. (2011). Trust and wellbeing. International Journal of Wellbeing. https://doi. org/10.5502/ijw.v1i1.3.

Kahneman, D., \& Deaton, A. (2010). High income improves evaluation of life but not emotional well-being. Proceedings of the National Academy of Sciences, 107(38), 16489-16493. https://doi.org/10.1073/ pnas. 1011492107.

Kahneman, D., \& Krueger, A. B. (2006). Developments in the measurement of subjective well-being. Journal of Economic Perspectives, 20(1), 3-24. https://doi.org/10.1257/089533006776526030.

Kahneman, D., Krueger, A. B., Schkade, D. A., Schwarz, N., \& Stone, A. A. (2004). A survey method for characterizing daily life experience: The day reconstruction method. Science, 306(5702), 1776-1780. https://doi.org/10.1126/science.1103572.

Kahneman, D., \& Riis, J. (2005). Living, and thinking about it: Two perspectives on life. In F. A. Huppert, N. Baylis, \& B. Keverne (Eds.), The science of well-being (p. 285-304). Oxford University Press. https ://doi.org/10.1093/acprof:oso/9780198567523.003.0011.

Kapteyn, A., Lee, J., Tassot, C., Vonkova, H., \& Zamarro, G. (2015). Dimensions of subjective well-being. Social Indicators Research, 123(3), 625-660. https://doi.org/10.1007/s11205-014-0753-0.

Kato, H., Asukai, N., Miyake, Y., Minakawa, K., \& Nishiyama, A. (1996). Post-traumatic symptoms among younger and elderly evacuees in the early stages following the 1995 Hanshin-Awaji earthquake in Japan. Acta Psychiatrica Scandinavica, 93(6), 477-481. https://doi.org/10.1111/j.1600-0447.1996. tb10680.x.

Kieny, C., Flores, G., Maurer, J. (2020). Assessing and decomposing gender differences in evaluative and emotional well-being among older adults in the developing World. Review of Economics of the Household (forthcoming).

Knabe, A., Rätzel, S., Schöb, R., \& Weimann, J. (2010). Dissatisfied with life but having a good day: Timeuse and well-being of the unemployed*: Time-use and well-being of the unemployed. The Economic Journal, 120(547), 867-889. https://doi.org/10.1111/j.1468-0297.2009.02347.x.

Krueger, A. B., \& Stone, A. A. (2014). Measuring subjective wellbeing: Progress and challenges. Science, 346(6205), 42-43. https://doi.org/10.1126/science.1256392.

López Ulloa, B. F., Møller, V., \& Sousa-Poza, A. (2013). How does subjective well-being evolve with age? a literature review. Journal of Population Ageing, 6(3), 227-246. https://doi.org/10.1007/s1206 2-013-9085-0.

Mastekaasa, A. (1993). Marital status and subjective well-being: A changing relationship? Social Indicators Research, 29(3), 249-276. https://doi.org/10.1007/BF01079515.

Neumark, D. (1988). Employers' discriminatory behavior and the estimation of wage discrimination. The Journal of Human Resources, 23(3), 279-295. https://doi.org/10.2307/145830.

OECD. (2013). OECD guidelines on measuring subjective well-being. Paris: OECD Publishing. https://doi. org/10.1787/9789264191655-en.

Pavot, W., Diener, E., Colvin, C. R., \& Sandvik, E. (1991). Further validation of the satisfaction with life scale: Evidence for the cross-method convergence of well-being measures. Journal of Personality Assessment, 57(1), 149-161. https://doi.org/10.1207/s15327752jpa5701_17.

Powdthavee, N. (2003). Is the structure of happiness equations the same in poor and rich countries? The case of South Africa. Working Paper. Coventry: University of Warwick, Department of Economics. Warwick economic research papers (No.675). 
Power, M. (2003). Development of a common instrument for quality of life. In A. Nosikov \& C. Gudex (Eds.), EUROHIS: Developing common instruments for health surveys (pp. 145-163). Amsterdam: IOS Press.

Schilling, O. (2006). Development of life satisfaction in old age: Another view on the "paradox". Social Indicators Research, 75(2), 241-271. https://doi.org/10.1007/s11205-004-5297-2.

Steptoe, A., Deaton, A., \& Stone, A. A. (2015). Subjective wellbeing, health, and ageing. Lancet, 385(9968), 640-648. https://doi.org/10.1016/S0140-6736(13)61489-0.

Steptoe, A., \& Wardle, J. (2012). Enjoying Life And Living Longer. Archives of Internal Medicine, 172(3), 273. https://doi.org/10.1001/archinternmed.2011.1028.

Stiglitz, J. E., Sen, A., \& Fitoussi, J. (2009). The measurement of economic performance and social progress revisited. The measurement of economic performance and social progress revisited. Commission on the measurement of economic performance and social progress, Paris.

Stone, A. A., Mackie, C. J., National Research Council (U.S.), \& National Research Council (U.S.) (Eds.). (2013). Subjective well-being: Measuring happiness, suffering, and other dimensions of experience. The National Academies Press.

Stone, A. A., Schwartz, J. E., Broderick, J. E., \& Deaton, A. (2010). A snapshot of the age distribution of psychological well-being in the United States. Proceedings of the National Academy of Sciences, 107(22), 9985-9990. https://doi.org/10.1073/pnas.1003744107.

Ticehurst, S., Webster, R. A., Carr, V. J., \& Lewin, T. J. (1996). The psychosocial impact of an earthquake on the elderly. International Journal of Geriatric Psychiatry, 11(11), 943-951. https://doi.org/10.1002/ (SICI)1099-1166(199611)11:11\%3c943:AID-GPS412\%3e3.0.CO;2-B.

United Nations. (2017). World population ageing 2015. UN. https://doi.org/10.18356/88fa44e7-en.

White, M. P., \& Dolan, P. (2009). Accounting for the richness of daily activities. Psychological Science, 20(8), 1000-1008. https://doi.org/10.1111/j.1467-9280.2009.02392.x.

Publisher's Note Springer Nature remains neutral with regard to jurisdictional claims in published maps and institutional affiliations. 